Article

\title{
Pricing, Green Degree and Coordination Decisions in a Green Supply Chain with Loss Aversion
}

\author{
Zhongwei Feng ${ }^{1(1)}$ and Chunqiao Tan ${ }^{1,2, *}$ (i) \\ 1 School of Business, Central South University, Changsha 410083, Hunan, China; 151601016@csu.edu.cn \\ 2 School of Economics and Management, Nanjing University of Information Science and Technology, \\ Nanjing 210044, Jiangsu, China \\ * Correspondence: chunqiaot@sina.com
}

Received: 26 January 2019; Accepted: 27 February 2019; Published: 6 March 2019

\begin{abstract}
The consumer environmental awareness promotes green manufacturing and the behavioral preferences of members become prevailing in supply chain management. To promote further development of green supply chains, a two-echelon green supply chain with a manufacturer and a retailer is considered, where the manufacturer is loss-averse and the retailer is risk-neutral. We use a Stackelberg game to investigate the impacts of loss aversion and green efficiency coefficient on retail price, wholesale price, green degree, profits of members, and profit of the green supply chain under the assumption that manufacturer's reference point of loss aversion is equal to the subgame perfect equilibrium partition. It is shown that, in the centralized decision-making setting (CDS), green degree and profit of the green supply chain are higher than those in the decentralized decision-making setting (DDS), while in the decentralized decision-making setting with a loss-averse manufacturer (DDS-LAM) loss aversion of manufacturer further decreases green degree and profit of green supply chain. It is also found that profits of the manufacturer and the retailer decrease with levels of loss aversion of manufacturer. Furthermore, it is also shown that wholesale price and retail price in the three decision-making settings depend on the green efficiency coefficient. Wholesale price and retail price in DDS-LAM are always the lowest (highest) if the green efficiency coefficient is sufficiently high (low). Finally, executing a greening cost-sharing contract can improve chain members' profits if the retailer shares an appropriate proportion with the loss-averse manufacturer.
\end{abstract}

Keywords: green supply chain management; green efficiency coefficient; loss aversion; reference point; greening cost-sharing contract

\section{Introduction}

With the continuous development of global industrialization, the living environment of human beings is being severely damaged [1], which makes the concept of sustainable development, including low-carbon economy and green GDP, receive extensive attention. Thus, green supply chain management (GSCM) is studied by more and more scholars [2,3]. The implementation of GSCM compels members of chain to reconsider some problems, such as product innovation and reverse logistics design [4-6]. As an important factor of greening activities, green manufacturing plays a critical role in GSCM [7]. Moreover, the environmental awareness can change consumers buying behavior. A number of works show that consumers are willing to pay more for environmentally friendly products than before $[8,9]$. For instance, a survey conducted by the European Commission in 2008 shows that $75 \%$ of Europeans are willing to purchase green products even if they have to pay a little more [10]. Furthermore, product innovation on green products can not only improve environment but also enhance manufacturers' competitive strength [11]. Thus, the top priority for GSCM is innovation for a higher green level [12]. Many manufacturers focus on green products to 
improve environment or increase competitive strength. For example, Patagonia, a clothing company in California, has produced green products for several years [13]. Adidas, a giant manufacturer, reduces the environmental impact by producing green products [12]. Another giant manufacturer, Pepsi-Cola, reduces the environmental impact by making use of reusable plastic shipping containers [14]. Lots of large manufacturers in China also devote to greening their products to protect environment or increase competitive strength. In the 2014 Appliance World Expo, Gree, Midea, Haier, and others displayed their newly launched energy-saving products to audiences (www.appliance-expo.com).

Green manufacturing, as the critical factor of greening activities in GSCM, compels manufacturers to invest heavily in new equipment or technology to protect environment or increase competitive strength, which causes manufacturers to pay more attention to gains or losses than to profits. For example, from 2016 to 2020, Shanghai General Motors will invest 26.5 billion yuan in efficient powertrain and new energy technology (http:/ / www.saic-gm.com/www/web/saic-gm/ -lvdongweilai1). In 2016, Yili's total investment in green production reached about 150 million yuan (http:/ /inews.nmgnews.com.cn/system/2017/02/10/012265324.shtml). Furthermore, abundant works in both psychological and the economic literature show that decision-makers are more motivated to minimize losses (relative to a reference point) than to maximize gains [15-19]. Thus, a natural assumption is that manufacturers are loss-averse. In real supply chain management, the behavioral preferences of manufacturers' loss aversion have an important effect on whether cooperation among chain members can be achievable. There are some examples where the channels are broken in supply chains since loss aversion of manufacturers is neglected by other members. For example, Langsha Group, the largest sock manufacturer of China, decided to terminate cooperation with Wal-Mart in 2007, since Langsha Group could no longer benefit from cooperation with Wal-Mart compared to direct selling (i.e., Langsha Group incurred losses). Xuzhou Wanji Trading of China, a distributor of Procter \& Gamble, decided to no longer cooperate with Procter \& Gamble in 2010, since Procter \& Gamble grabbed too much profit to make the former incur losses.

The idea of loss aversion is introduced by Kahneman and Tversky [16]. Tversky and Kahneman introduced a value function to characterize loss aversion of a decision-maker [19], which is applied to supply chain management. In their model, the loss-aversion parameter is accurately obtained by experimental data, that is, the loss-aversion parameter is a given coefficient. A given loss-aversion parameter cannot sufficiently reflect the decision-maker's levels of loss aversion. To deal with this problem, we adopt a simplified version proposed by Shalev [20]. In Shalev's version, the loss -aversion coefficient is constant for losses compared to a fixed reference outcome and across different reference points [21]. Additionally, the decision-maker's preference depends on a basic utility function, a reference point and a loss-aversion coefficient; outcomes below some reference point are regarded as losses and the utility of such outcomes are scaled down by the loss-aversion coefficient.

It is worthwhile to note that in the value function the decision-maker's reference point is equal to zero. It is reasonable under the theoretic framework of Tversky and Kahneman [19]. However, an important issue is still left behind that the reference point cannot capture the decision-maker's reference dependence endogenously emphasized by Tversky and Kahneman [22]. To address this issue, the subgame perfect equilibrium partition in the Rubinstein alternating-offers bargaining game is introduced as a reference point to formally depict perceptively loss compromise in this paper. According to Rubinstein [23], since the alternating-offers bargaining game accurately captures patience endogenously and the bargaining process between two players, the subgame perfect equilibrium partition is regarded as representing all anticipations that both players might agree on as fair bargains. Some properties (i.e., no delay, stationarity, and accept-reject indifference) that are used to characterize the subgame perfect equilibrium partition are appealing in defining the loss-averse reference dependence [24]. Players' reference points are equal to the highest rejected offer of their opponent in the past bargaining rounds, since this offer can be regarded as the share that players could have obtained so far [24]. That is, the subgame perfect equilibrium partition gives how much one should deserve from the overall material payoff. Thus, the subgame perfect equilibrium partition 
can be regarded as loss-averse reference points [24]. The subgame perfect equilibrium partition as a reference point of loss aversion is our first contribution. In the long-term bargaining process, both players will gradually reach agreement on this loss-averse reference point, even though there does not exist such a real alternating-offers bargaining process. Note that the alternating-offers bargaining game is just a psychological game that is more likely to lie in the decision-makers' mind than really happen.

It is easy to find some literature that considers bargaining games and Stackelberg games simultaneously, such as Huang and Li and Du et al. [25,26]. Huang and Li investigated the impact of vertical cooperative advertising efficiency on transactions between a manufacturer and a retailer. In their model, the manufacturer and the retailer play a Stackelberg game first to make an overall material payoff (or a "pie") and then bargain how to divide the payoff (or the "pie") by the Nash bargaining model, while Du et al. used the Nash bargaining model to form the fairness reference of the two members in members' own minds first and then play a Stackelberg game based on this fairness reference. The Nash bargaining model really happens in the second stage [25] while it happens in minds in the first stage [26]. In this paper, the alternating-offers bargaining game and the Stackelberg game are considered simultaneously. The idea of this paper is similar to that of $\mathrm{Du}$ et al., i.e., the alternating-offers bargaining game is used to form manufacturer's loss-averse reference point in members' own minds first and then members play a Stackelberg game based on this reference point. The second contribution is to show how the alternating-offers bargaining game and the Stackelberg game can be used simultaneously in the GSCM.

Our third contribution is that we discuss whether the coordination of the green supply chain with a loss-averse manufacturer and a risk-neutral retailer can be achievable. It turns out that the greening cost-sharing contract can achieve coordination of this green supply chain as long as the retailer shares an appropriate proportion of greening cost with the loss-averse manufacturer.

Our paper aims at providing some insights into the following questions:

1. What are the loss-averse manufacturer's optimal wholesale price and green degree and what is the risk-neutral retailer's optimal retail price?

2. What effect does behavioral preference of loss aversion for the manufacturer have on retailer's optimal retail price and manufacturer's optimal wholesale price and green degree?

3. What effect does loss aversion for the manufacturer have on profits of chain members and green supply chain?

4. To achieve coordination of green supply chain with a loss-averse manufacturer and a risk-neutral retailer, what greening cost-sharing contract does the manufacturer and retailer execute?

This paper continues as follows. In Section 2, relevant literature is reviewed. In Section 3, we introduce some assumptions, construct models in different decision-making settings, and perform comparative analysis of results. In Section 4 , a greening cost-sharing contract is considered. In Section 5 , a numerical analysis is given. In Section 6, conclusions and directions for future research are shown.

\section{Literature Review}

Here, we review relevant literature, including literature on GSCM and traditional supply chain management with loss-averse members.

\subsection{Green Supply Chain Management}

The extant literature on GSCM is investigated from different perspectives, such as game theoretic models, supply chain coordination, government influences, and dual-channel supply chain. For instance, Song and Gao constructed a green supply chain game model with two kinds of revenue-sharing contracts (i.e., retail-led revenue-sharing contract and the bargaining revenue-sharing contract) and concluded that the revenue-sharing contract can promote the cooperation among members [27]. Liu and Yi established four different green supply chain game models to explore optimal pricing policies. They found that optimal retail and wholesale prices are negatively related to 
the degree of greening level [28]. Ghosh and Shah explored green supply chain coordination issues and the effect of a cost-sharing contract on the critical decision of chain members. They claimed that the cost-sharing contract always increases the degree of greening level of the product [29]. Basiri and Heydari investigated the green supply chain coordination issue under the assumption that the demand is a function of retail price, products' green quality, and retailer's sales efforts [30]. Sheu and Chen used a three-stage game model to investigate the impact of governmental intervention on green supply chain competition. Numerical results reveal that compared with the case without government intervention, social welfare- and chain-based profits improve by $27.8 \%$ and $306.6 \%$, respectively [31]. Yang and Xiao developed three different green supply chain game models to investigate the impact of governmental interventions on green supply chain under fuzzy environment. It is found that a retailer Stackelberg game model is superior to a manufacturer Stackelberg game model under the strong intervention from government [32]. Jamali and Rasti-Barzoki investigated the performance of two-competitor green supply chains with dual-distribution channels and found that the selling of green products can bring competitive advantages [33]. Xing et al. constructed a game model where one manufacturer sells a green product, while the other sells a conventional product in the same consumer market. They found that the green manufacturer adopts the integrated channel strategy [34]. Dai et al. investigated the effects of cartelization and cost-sharing contract on a green supply chain. They found that the manufacturer generally prefers cartelization to the cost-sharing contract while the retailer prefers the cost-sharing contract to cartelization [35].

\subsection{Traditional Supply Chain Management with Loss-Averse Members}

Loss aversion is generally formalized by incorporating profit disparity into the utility function, which is characterized by the value function [19] and applied to supply chain management. For example, Eeckhoudt et al. and Schweitzer and Cachon found that a newsvendor with a loss-averse preference always orders less than one with a risk-neutral preference [36,37]. In addition, Schweitzer and Cachon found that the optimal order quantity of newsvendor is negatively related to the levels of loss aversion [37]. Suo et al. investigated the impact of a loss-averse newsvendor on a vendor-managed inventor [38]. Wang and Webster found that the supply chain with a loss-averse retailer and a risk-neutral supplier can be coordinated by gain/loss-sharing-and-buyback contracts [39]. Wang and Webster extended the model proposed by Schweitzer and Cachon [37] to incorporate shortage costs. They claimed that the loss-averse newsvendor's optimal order quantity increases in wholesale price while decreasing in retail price when the shortage cost is not negligible [40]. Wu et al. found that the optimal inventory level of the decentralized supply chain is negatively related to the retailer's level of loss aversion [41]. Du et al. investigated a two-echelon supply chain under the assumption that a supplier with yield randomness and a retailer with demand uncertainty are loss-averse. They found that the optimal order quantity of retailer with loss aversion may increase in wholesale price and decrease in retail price [42].

A comparison table is provided to highlight the research gaps and contributions of closely related papers, as shown in Table 1.

The extant literature on GSCM is studied under the assumption that members of chain are rational. In addition, the extant literature on loss-averse agents focuses on traditional supply chain management. However, in the real GSCM, since manufacturers have to invest heavily in new equipment or technology before producing green products, which causes manufacturers to pay more attention to gains or losses than to profits. Such behavioral preferences for manufacturers cause expected utility (i.e., hypothesis of rational man) to fails to adequately describe human behavior. In particular, abundant works in both psychological and economic literature show that decision-makers are more motivated to minimize losses (relative to a reference point) than to maximize gains. Thus, this paper assumes that the manufacturer is loss-averse. On the other hand, it is worthwhile noting that the extant literature on supply chain management with loss-averse agents is studied based on the value function introduced by Kahneman and Tversky [19]. In this model, the loss-aversion parameter is 
accurately obtained by experimental data such that such a loss-aversion parameter cannot sufficiently capture decision-maker's levels of loss aversion. In addition, in this version, the decision-maker's reference point is equal to zero, which has its limitation, since a profit-seeking firm may not expect such a reference point. To address such problems, our study adopts a simple and elegant version introduced by Shalev to capture manufacturer's loss aversion and determines the manufacturer's reference point by the alternating-offers bargaining game.

Table 1. The classification of literature in supply chain management.

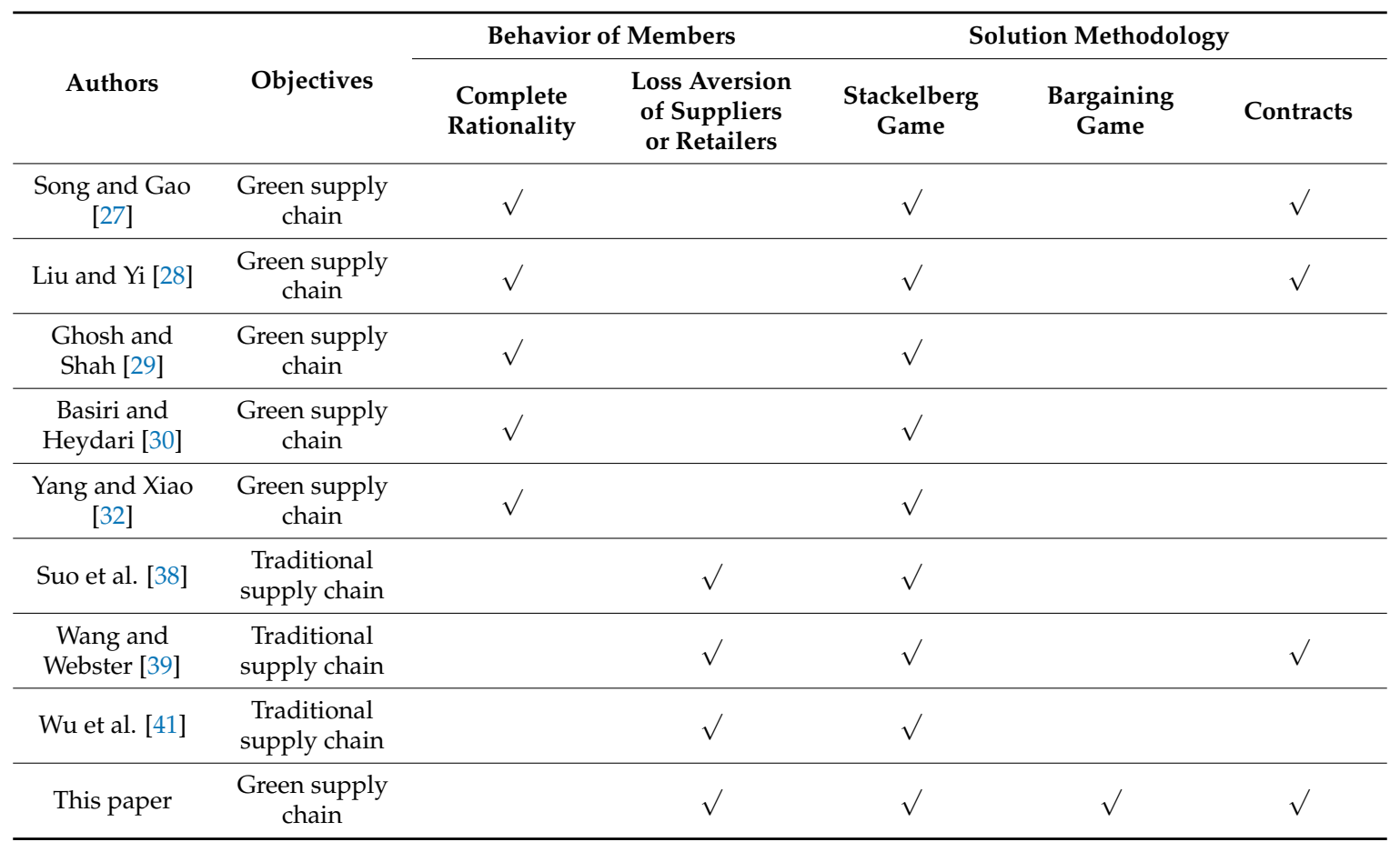

\section{Model Formulation and Analysis}

Figure 1 depicts a green supply chain with a manufacturer, a retailer, and consumers. In this system, the manufacturer engages in the green manufacturing by investing heavily in new equipment or technology such that the manufacturer can increase competitive strength or protect environment. Manufacturing green products increases costs per unit of output (i.e., the greening cost). That is, the manufacturer has to invest certain greening cost per unit of green product. As the selling season is drawing near, the manufacturer and the retailer play a Stackelberg game to decide wholesale price, green degree and retail price, where the manufacturer plays the role of the leader and the retailer plays the role of the follower. The manufacturer first decides wholesale price and green degree by the manufacturing cost and the greening cost. Then, the retailer decides retail price with wholesale price and green degree given by the manufacturer.

Some assumptions are shown as follows.

Assumption 1. The demand faced by the manufacturer and the retailer are a linear function of retail price and green degree, which is similar to the demand function where the demand increases with advertising [43]. According to Liu et al. [44] and Swami and Shah [45], the demand function is presented as follows:

$$
q=a+\tau e-p
$$

where $a$ is the basic market demand of the green products, which represents the market potential, e is the green degree of the green product, $\tau$ is the consumer sensitivity to green improvements, and $p$ is the retail price per unit of the green product. 
Assumption 2. Producing green products has no impact on the traditional marginal costs. To produce green products, the manufacturer has to invest in heavily new equipment or technology. The cost is a quadratic function of green degree $[13,44]$. The extra cost for the manufacturer to produce green products (i.e., greening cost of products) is $h e^{2} / 2$, where $h$ is the cost coefficient of green degree per unit.

Assumption 3. The information between the manufacturer and the retailer are complete and symmetry [43,46].

It follows from Assumptions 1 and 2 that manufacturer's profit $\pi_{m}$ and retailer's profit $\pi_{r}$ are shown as follows, respectively:

$$
\pi_{m}(p, e, w)=(a+\tau e-p)(w-c)-\frac{1}{2} h e^{2},
$$

and

$$
\pi_{r}(p, e, w)=(a+\tau e-p)(p-w)
$$

where $w$ is the wholesale price per unit of the green product, and $c$ is the manufacturing cost per unit of the green product.

By combining Equations (2) and (3), the profit of the entire green supply chain $\pi_{s c}$ is shown as follows:

$$
\pi_{s c}(p, e)=(a+\tau e-p)(p-c)-\frac{1}{2} h e^{2},
$$

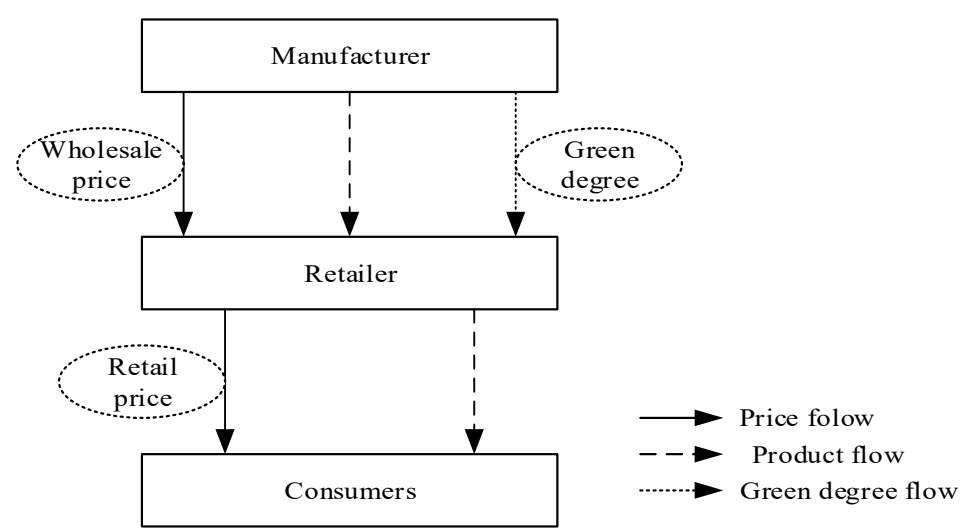

Figure 1. Green supply chain with an environmentally conscious manufacturer, a retailer, and consumers.

\subsection{The Model with a Risk-Neutral Manufacturer}

\subsubsection{Centralized Decision-Making Model with a Risk-Neutral Manufacturer}

In the centralized decision-making setting (CDS), the manufacturer and the retailer aim at maximizing the profit of the entire green supply chain. In this case, the Hessian matrix on retail price $p$ and green degree $e$ is shown as follows:

$$
\left(\begin{array}{cc}
-2 & \tau \\
\tau & -h
\end{array}\right)
$$

The Hessian matrix is negative definite if $2 h-\tau^{2}>0$ (i.e., $0<\tau^{2} / h<2$, where $\tau^{2} / h$ is defined as the green efficiency coefficient of products). It means that the profit function given by Equation (4) is a joint concave function of $p$ and $e$. Thus, there exists the unique retail price $p^{*}$ and the green degree $e^{*}$ such that the profit of the entire green supply chain is maximum. After taking the first derivative of 
Equation (4) with respect to $p$ and $e$, respectively, and letting these derivatives be equal to zero, retail price $p^{*}$ and green degree $e^{*}$ are given as follows:

$$
e^{*}=\frac{\tau(a-c)}{2 h-\tau^{2}}, p^{*}=c+\frac{(a-c) h}{2 h-\tau^{2}}
$$

Substituting Equations (6) into (4) yields the profit of the entire green supply chain:

$$
\pi_{s c}\left(p^{*}, e^{*}\right)=\frac{h(a-c)^{2}}{2\left(2 h-\tau^{2}\right)}
$$

\subsubsection{Decentralized Decision-Making Model with a Risk-Neutral Manufacturer}

In the decentralized decision-making setting (DDS), the manufacturer and the retailer intend to maximize their own profits, respectively. In this case, we construct a Stackelberg game model. The manufacturer and the retailer sequentially decide wholesale price $w$, green degree $e$ and retail price $p$. After taking the first derivative of Equation (3) with respect to $p$, the reaction function of retail price $p$ is given by:

$$
p=(a+w+\tau e) / 2 .
$$

This results in manufacturer's profit function:

$$
\pi_{m}(e, w)=[a+\tau e-(a+w+\tau e) / 2](w-c)-h e^{2} / 2 .
$$

The Hessian matrix on wholesale price $w$ and green degree $e$ is:

$$
\left(\begin{array}{cc}
-1 & \tau / 2 \\
\tau / 2 & -h
\end{array}\right)
$$

The Hessian matrix is negative definite if $4 h-\tau^{2}>0$ (i.e., $0<\tau^{2} / h<4$ ). It means that the profit function given by Equation (9) is a joint concave function of wholesale price $w$ and green degree $e$. After taking the first derivative of Equation (9) with respect to $w$ and $e$, respectively, and letting these derivatives be equal to zero, wholesale price $w_{D}^{*}$ and green degree $e_{D}^{*}$ are:

$$
w_{D}^{*}=c+\frac{2 h(a-c)}{4 h-\tau^{2}} ; e_{D}^{*}=\frac{\tau(a-c)}{4 h-\tau^{2}}
$$

Substituting Equations (10) into (8) yields retail price $p_{D}^{*}$ :

$$
p_{D}^{*}=c+\frac{3 h(a-c)}{4 h-\tau^{2}} .
$$

Substituting Equations (10) and (11) into (2) yields manufacturer's profit $\pi_{m}^{D}$ :

$$
\pi_{m}^{D}=\frac{h(a-c)^{2}}{2\left(4 h-\tau^{2}\right)}
$$

Substituting (10) and (11) into (3) yields retailer's profit $\pi_{r}^{D}$ :

$$
\pi_{r}^{D}=\frac{h^{2}(a-c)^{2}}{\left(4 h-\tau^{2}\right)^{2}}
$$


Substituting (10) and (11) into (4) yields the profit of the entire green supply chain $\pi_{s c}^{D}$ :

$$
\pi_{s c}^{D}=\frac{h(a-c)^{2}\left(6 h-\tau^{2}\right)}{2\left(4 h-\tau^{2}\right)^{2}}
$$

\subsection{The Model with a Loss-Averse Manufacturer}

\subsubsection{Modelling Loss Aversion with a Subgame Perfect Equilibrium Reference}

In a green supply chain, manufacturers have to invest heavily in new equipment or technology before producing green products, which causes manufacturers to pay more attention to gains or losses than to profits. Since abundant works in both psychological and economic literature show that decision-makers are more motivated to minimize the losses (relative to a reference point) than to maximize gains, we assume that the manufacturer in a green supply chain with a manufacturer and a retailer is loss-averse in this paper. For the manufacturer with loss aversion, the preference is characterized by a basic utility function, a reference point, and a loss-aversion coefficient. If outcomes are less than some reference point, then they are regarded as losses. Additionally, the utility values of outcomes below some reference point are scaled down by the loss aversion factor. Let $\pi_{m}$ be denoted by the realized material payoff of the manufacturer, and let $v_{m}$ be denoted by the manufacturer's reference point. We assume that manufacturer's basic utility is equal to $\pi_{m}$, but that $\pi_{m}$ below the reference point $v_{m}$ is regarded as a loss and scaled down by a loss-aversion coefficient $\lambda_{m}\left(\lambda_{m} \geq 0\right)$. More precisely, the loss-averse manufacturer evaluates $\pi_{m}$ by the following function [20]:

$$
u_{m}= \begin{cases}\pi_{m} & \pi_{m} \geq v_{m} \\ \pi_{m}-\lambda_{m}\left(v_{m}-\pi_{m}\right) & \pi_{m}<v_{m}\end{cases}
$$

or

$$
u_{m}=\left(1+\lambda_{m}\right) \pi_{m}-\lambda_{m} \max \left\{v_{m}, \pi_{m}\right\}
$$

The function given by (15) is similar to the value function introduced by Tversky and Kahneman [19]. The value function has an approximate form $\left(\pi_{m}\right)^{\alpha}$ for $\pi_{m} \geq 0$ and $-\lambda_{m}\left(-\pi_{m}\right)^{\alpha}$ for $\pi_{m}<0$, where 0 is the reference point. $\alpha$ and $\lambda_{m}$ values found experimentally by Tversky and Kahneman are equal to 0.88 and 2.25, respectively [19]. The function given by (15) retains the loss-aversion aspect: the function is steeper for losses than for gains. The loss-aversion coefficients are different for different decision-makers, which can reflect the heterogeneity of loss aversion.

Furthermore, we introduce the Rubinstein alternating-offers bargaining game to determine the reference point of the manufacturer, i.e., the subgame perfect equilibrium partition is regarded as the manufacturer's reference point, since some properties (i.e., no delay, stationarity, and accept-reject indifference) that are used to characterize the subgame perfect equilibrium partition are appealing in defining the loss-averse reference dependence [24]. Thus, we need the following lemma as a prerequisite.

Lemma 1. In a supply chain with a loss-averse manufacturer and a risk-neutral retailer, the loss-averse reference point for the manufacturer is:

$$
v_{m}^{*}=\frac{\left(1+\lambda_{m}(1-\delta)\right) \pi_{s c}}{1+\lambda_{m}+\delta} .
$$

where $\delta$ is the probability of continuation about the bargaining game after rejection.

Proof. See Appendix A. 
3.2.2. Decentralized Decision-Making Model with a Loss-Averse Manufacturer

In the decentralized decision-making setting with a loss-averse manufacturer (DDS-LAM), the manufacturer intends to maximize his own utility $u_{m}$. Since the manufacturer's reference point is $v_{m}^{*}=\left(1+\lambda_{m}(1-\delta)\right) \pi_{s c} /\left(1+\lambda_{m}+\delta\right)$, the utility $u_{m}$ is:

$$
u_{m}= \begin{cases}\pi_{m} & \pi_{m} \geq v_{m}^{*} \\ \left(1+\lambda_{m}\right) \pi_{m}-\lambda_{m} v_{m}^{*} & \pi_{m}<v_{m}^{*}\end{cases}
$$

If $\pi_{m} \geq v_{m}^{*}$, then $u_{m}=\pi_{m}$. On the other hand, the retailer is risk-neutral, which means that retailer's utility $u_{r}=\pi_{r}$. In this case, the outcomes, such as wholesale price, green degree, retail price, manufacturer's profit, retailer's profit, and the profit of the entire green supply chain, are identical to those in the decentralized decision-making case where the manufacturer is risk-neutral (see Section 3.1.2).

If $\pi_{m}<v_{m}^{*}$, then the utility of loss-aversion manufacturer is:

$$
u_{m}=\left(1+\lambda_{m}\right) \pi_{m}-\frac{\lambda_{m}\left(1+\lambda_{m}(1-\delta)\right) \pi_{s c}}{1+\lambda_{m}+\delta}
$$

Retailer's utility is:

$$
u_{r}=\pi_{r}
$$

We construct a Stackelberg game model in which the manufacturer first announces. The manufacturer and the retailer sequentially decide on wholesale price $w$, green degree $e$, and retail price $p$. After taking the first derivative of (18) with respect to $p$, the reaction function of retail price $p$ is given by:

$$
p=\frac{a+w+\tau e}{2}
$$

Substituting (19) into (17) yields the utility of loss-aversion manufacturer $u_{m}$ :

$$
\begin{aligned}
u_{m}= & \left(1+\lambda_{m}\right)\left\{[a+\tau e-(a+w+\tau e) / 2](w-c)-h e^{2} / 2\right\}- \\
& \lambda_{m}\left(1+\lambda_{m}(1-\delta)\right)\left\{(a+\tau e-(a+w+\tau e) / 2)((a+w+\tau e) / 2-c)-h e^{2} / 2\right\} /\left(1+\lambda_{m}+\delta\right) .
\end{aligned}
$$

It is easy to prove that the Hessian matrix on wholesale price $w$ and green degree $e$ is negative definite. After taking the first derivative of (20) with respect to $w$ and $e$, respectively, and letting these derivatives be equal to zero, then wholesale price $w_{\lambda_{m}}^{D *}$ and green degree $e_{\lambda_{m}}^{D *}$ are:

$$
\begin{gathered}
w_{\lambda_{m}}^{D *}=c+\frac{2 h\left(1+\lambda_{m}+\delta\right)\left(1+\lambda_{m}\right)(a-c)}{\left(1+\lambda_{m}\right)(1+\delta)\left(4 h-\tau^{2}\right)+\delta \lambda_{m}^{2}\left(2 h-\tau^{2}\right)+2 h \lambda_{m}\left(1+\lambda_{m}\right)} \\
e_{\lambda_{m}}^{D *}=\frac{\left(\left(1+\lambda_{m}\right)\left(1+\delta \lambda_{m}\right)+\delta\right)(a-c) \tau}{\left(1+\lambda_{m}\right)(1+\delta)\left(4 h-\tau^{2}\right)+\delta \lambda_{m}^{2}\left(2 h-\tau^{2}\right)+2 h \lambda_{m}\left(1+\lambda_{m}\right)}
\end{gathered}
$$

Substituting (21) and (22) into (19) yields:

$$
p_{\lambda_{m}}^{D *}=c+\frac{h\left((\delta+2) \lambda_{m}^{2}+3 \delta\left(1+\lambda_{m}\right)+5 \lambda_{m}+3\right)(a-c)}{\left(1+\lambda_{m}\right)(1+\delta)\left(4 h-\tau^{2}\right)+\delta \lambda_{m}^{2}\left(2 h-\tau^{2}\right)+2 h \lambda_{m}\left(1+\lambda_{m}\right)}
$$

Thus, manufacturer's profit, retailer's profit, and the profit of the entire green supply chain are obtained, respectively:

$$
\pi_{m, \lambda_{m}}^{D *}=\frac{h\left(1+\lambda_{m}+\delta+\delta \lambda_{m}\left(1+\lambda_{m}\right)\right)\left(4\left(1+\lambda_{m}+\delta\right)\left(1+\lambda_{m}\right) h-\left(1+\lambda_{m}+\delta+\delta \lambda_{m}\left(1+\lambda_{m}\right)\right) \tau^{2}\right)(a-c)^{2}}{2\left(\left(1+\lambda_{m}\right)(1+\delta)\left(4 h-\tau^{2}\right)+\lambda_{m}^{2} \delta\left(2 h-\tau^{2}\right)+2 h \lambda_{m}\left(1+\lambda_{m}\right)\right)^{2}}
$$




$$
\begin{gathered}
\pi_{r, \lambda_{m}}^{D *}=\frac{h^{2}\left(1+\lambda_{m}+\delta+\delta \lambda_{m}\left(1+\lambda_{m}\right)\right)^{2}(a-c)^{2}}{\left(\left(1+\lambda_{m}\right)(1+\delta)\left(4 h-\tau^{2}\right)+\lambda_{m}^{2} \delta\left(2 h-\tau^{2}\right)+2 h \lambda_{m}\left(1+\lambda_{m}\right)\right)^{2}} \\
\pi_{s c, \lambda_{m}}^{D *}=\frac{h\left(1+\lambda_{m}+\delta+\delta \lambda_{m}\left(1+\lambda_{m}\right)\right)\left(\delta \lambda_{m}^{2}\left(2 h-\tau^{2}\right)+(1+\delta)\left(1+\lambda_{m}\right)\left(6 h-\tau^{2}\right)+4 h \lambda_{m}\left(1+\lambda_{m}\right)\right)(a-c)^{2}}{2\left(\left(1+\lambda_{m}\right)(1+\delta)\left(4 h-\tau^{2}\right)+\lambda_{m}^{2} \delta\left(2 h-\tau^{2}\right)+2 h \lambda_{m}\left(1+\lambda_{m}\right)\right)^{2}}
\end{gathered}
$$

\subsection{Comparative Analysis of Results}

In this subsection, the comparative analysis among different decision-making settings will be carried out.

Proposition 1. For wholesale price, we have: (i) If $0<\tau^{2} / h<2$, then $w_{\lambda_{m}}^{D *}>w_{D^{*}}^{*}$; (ii) If $\tau^{2} / h=2$, then $w_{\lambda_{m}}^{D *}=w_{D^{\prime}}^{*}$ (iii) If $2<\tau^{2} / h<4$, then $w_{\lambda_{m}}^{D *}<w_{D}^{*}$.

Proof. See Appendix B.

Remark 1. From Proposition 1, it follows that the green efficiency coefficient of products has a critical impact on wholesale price. In case ( $i$ ), if the green efficiency coefficient of products is lower than the threshold, then the wholesale price in DDS-LAM is higher than that in DDS, while the result is reversed when the green efficiency coefficient of products is sufficiently high, as shown in case (iii). If the green efficiency coefficient of products is moderate, then the wholesale price in DDS-LAM is identical to that in DDS, as shown in case (ii).

Proposition 2. For retail price, we have: (i) If $0<\tau^{2} / h<1$, then $p_{\lambda_{m}}^{D *}>p_{D}^{*}>p^{*}$; (ii) If $\tau^{2} / h=1$, then $p_{\lambda_{m}}^{D *}=p_{D}^{*}=p^{*}$; (iii) If $1<\tau^{2} / h<2$, then $p_{\lambda_{m}}^{D *}<p_{D}^{*}<p^{*}$.

Proof. See Appendix C.

Remark 2. Based on Proposition 2, in case (i), when the green efficiency coefficient of products is sufficiently low, the retail price is the highest in DDS-LAM, while it is the lowest in CDS. We obtain a reversed result if the green efficiency coefficient of products is sufficiently high, as shown in case (iii). In addition, in case (i), the retail price in DDS is higher than that in CDS, which is identical to the case of the traditional supply chain. In the green supply chains, market demand depends on retail price and green degree of products. A lower green efficiency coefficient of products cannot result in a significant increase in market demand. Thus, the decision-making result in the green supply chains is similar to the result in the traditional supply chains. If the green efficiency coefficient of products is sufficiently high, the retail price in DDS is lower than that in CDS, which is a reversed result compared to the case of the traditional supply chains. In this situation, a higher level of environmental awareness causes consumers to purchase higher-green-degree products. Moreover, a higher green efficiency coefficient of products leads to dramatically increasing market demand. Thus, we obtain the reversed results between the green supply chains and the traditional supply chains.

Proposition 3. For green degree, we have $e_{\lambda_{m}}^{D *}<e^{D *}<e^{*}$.

Proof. See Appendix D

Remark 3. It follows from Proposition 3 that the green degree is the lowest in DDS-LAM, followed by that in the DDS, while it is the highest in the CDS. The manufacturer with loss aversion is not willing to invest in new equipment or technology to produce the green products, which leads to a low green degree of products.

Proposition 4. (i) For manufacturer's profit, we have $\pi_{m, \lambda_{m}}^{D *}<\pi_{m}^{D}$. (ii) For retailer's profit, we have $\pi_{r, \lambda_{m}}^{D *}<$ $\pi_{r}^{D}$. (iii) For the profit of the entire green supply chain, we have $\pi_{s c, \lambda_{m}}^{D *}<\pi_{s c}^{D}<\pi_{s c}\left(p^{*}, e^{*}\right)$.

Proof. See Appendix E. 
Assumption 4. From case (i) of Proposition 4, we know that manufacturer's profit in DDS-LAM is lower than that in DDS. Compared with the risk-neutral manufacturer, the manufacturer with loss aversion is hurt by his own loss aversion. In other words, the manufacturer cannot benefit from his own loss aversion. From case (ii) of Proposition 4, it follows that retailer's profit in DDS-LAM is lower than that in DDS. It means that compared with the case of cooperating with the risk-neutral manufacturer, the retailer is hurt by the manufacturer's loss aversion. From Propositions 4, the manufacturer's behavioral preference of loss aversion decreases the profits of chain members, that is, the loss-averse manufacturer is willing to sacrifice part of his own profit and take actions to punish the retailer such that the manufacturer maintains the gains. In case (iii) of Proposition 4, the profit of the entire green supply chain is the highest in CDS, followed by DDS, while it is the lowest in DDS-LAM. If the manufacturer and the retailer aim at maximizing their own profits, then the profit of the entire green supply chain is decreased compared with that in the CDS. If the manufacturer is loss-averse, then he intends to optimize the utility of loss aversion. Compared with the case of optimizing profit, the manufacturer pays attention to the losses or the gains. In this situation, the manufacturer's decision will further decrease the profit of the entire green supply chain.

\section{Greening Cost-Sharing Contract Model with a Loss-Averse Manufacturer}

The consumers' environmental awareness compels the manufacturer to manufacture the green products by investing heavily in new equipment or technology. Incurred investment cost in greening products leads to decreasing the manufacturer' profit in the short term such that the manufacturer lacks motivation to produce green products. This results in two questions: Are the manufacturer' incentive for manufacturing green products aligned? What incentive scheme can boost the manufacturer to manufacture green products? To address the two questions, in this section, the retailer offers the incentive scheme- - a greening cost-sharing contract that the retailer is willing to share some greening cost with the manufacturer. Let $\phi$ be denoted by the proportion of greening cost shared by that the retailer shares with the manufacturer. Then, the respective profits of the manufacturer and the retailer are shown as:

$$
\bar{\pi}_{m}(p, e, w)=(a+\tau e-p)(w-c)-\frac{1}{2}(1-\phi) h e^{2}
$$

and

$$
\bar{\pi}_{r}(p, e, w)=(a+\tau e-p)(p-w)-\frac{1}{2} \phi h e^{2}
$$

Since the manufacturer is loss-averse, then the manufacturer aims at pursuing the maximization of utility. The utility of the manufacturer is:

$$
\bar{u}_{m}= \begin{cases}\bar{\pi}_{m} & \bar{\pi}_{m} \geq v_{m}^{*} \\ \left(1+\lambda_{m}\right) \bar{\pi}_{m}-\lambda_{m} v_{m}^{*} & \bar{\pi}_{m}<v_{m}^{*}\end{cases}
$$

where $v_{m}^{*}=\left(1+\lambda_{m}(1-\delta)\right) \pi_{s c} /\left(1+\lambda_{m}+\delta\right)$.

To analyze the impact of loss aversion on green supply chains, we restrict ourselves to the case $\bar{\pi}_{m}<v_{m}^{*}$. In this case, the manufacturer's utility is:

$$
\bar{u}_{m}=\left(1+\lambda_{m}\right) \bar{\pi}_{m}-\frac{\lambda_{m}\left(1+\lambda_{m}(1-\delta)\right) \pi_{s c}}{1+\lambda_{m}+\delta}
$$

The retailer's utility is:

$$
\bar{u}_{r}=\bar{\pi}_{r}
$$


We construct a Stackelberg game model, where the manufacturer plays the role of the leader and the retailer plays the role of the follower. The manufacturer and the retailer sequentially decide on wholesale price $w$, green degree $e$ and retail price $p$. Differentiating (31) with respect to $p$ yields:

$$
p=\frac{a+w+\tau e}{2}
$$

Substituting (32) into (30) yields manufacturer's utility:

$$
\begin{aligned}
\bar{u}_{m}= & \left(1+\lambda_{m}\right)\left\{[a+\tau e-(a+w+\tau e) / 2](w-c)-(1-\phi) h e^{2} / 2\right\}- \\
& \lambda_{m}\left(1+\lambda_{m}(1-\delta)\right)\left\{(a+\tau e-(a+w+\tau e) / 2)((a+w+\tau e) / 2-c)-h e^{2} / 2\right\} /\left(1+\lambda_{m}+\delta\right) .
\end{aligned}
$$

The Hessian matrix on wholesale price $w$ and green degree $e$ is:

$$
\left(\begin{array}{cc}
-1-\lambda_{m}+\frac{\lambda_{m}\left(1+\lambda_{m}(1-\delta)\right)}{2\left(1+\lambda_{m}+\delta\right)} & \frac{\left(1+\lambda_{m}\right) \tau}{2} \\
\frac{\left(1+\lambda_{m}\right) \tau}{2} & -(1-\phi) h\left(1+\lambda_{m}\right)+\frac{\lambda_{m}\left(1+\lambda_{m}(1-\delta)\right)\left(2 h-\tau^{2}\right)}{4\left(1+\lambda_{m}+\delta\right)}
\end{array}\right)
$$

The Hessian matrix is negative definite if

$$
\left(\delta \lambda_{m}^{2}+\delta \lambda_{m}+\lambda_{m}+\delta+1\right)^{2}\left(2 h-\tau^{2}\right)+2 h\left(1+\lambda_{m}\right)\left(1+\lambda_{m}+\delta\right)\left[\left(\delta \lambda_{m}^{2}+\delta \lambda_{m}+\lambda_{m}+\delta+1\right)(1-\phi)-\left(1+\lambda_{m}\right)\left(1+\lambda_{m}+\delta\right) \phi\right]>0
$$

i.e.,

$$
\begin{aligned}
\frac{\tau^{2}}{h} & <2+\frac{2\left(1+\lambda_{m}\right)\left(1+\lambda_{m}+\delta\right)\left[\left(\delta \lambda_{m}^{2}+\delta \lambda_{m}+\lambda_{m}+\delta+1\right)(1-\phi)-\left(1+\lambda_{m}\right)\left(1+\lambda_{m}+\delta\right) \phi\right]}{\left(\delta \lambda_{m}^{2}+\delta \lambda_{m}+\lambda_{m}+\delta+1\right)^{2}} \\
& <2+\frac{\left(1+\lambda_{m}\right)\left(1+\lambda_{m}+\delta\right)(1-2 \phi)}{\delta \lambda_{m}^{2}+\delta \lambda_{m}+\lambda_{m}+\delta+1} .
\end{aligned}
$$

Thus, wholesale price $w_{\lambda_{m}}^{\phi, D *}$ and green degree $e_{\lambda_{m}}^{\phi, D *}$ are shown, respectively:

$$
\begin{aligned}
& w_{\lambda_{m}}^{\phi, D *}=c+\frac{2 h\left(1+\lambda_{m}+\delta\right)\left(1+\lambda_{m}\right)\left(1+\lambda_{m}+\delta-\phi-\phi \delta \lambda_{m}-\phi \lambda_{m}^{2}+\delta \lambda_{m}^{2}-\phi \delta-2 \phi \lambda_{m}+\delta \lambda_{m}\right)(a-c)}{\left\{\left(\delta \lambda_{m}^{2}+\delta \lambda_{m}+\delta+\lambda_{m}+1\right)\left[2 h\left(\delta \lambda_{m}^{2}+2 \delta \lambda_{m}+\lambda_{m}^{2}+2 \delta+3 \lambda_{m}+2\right)-\left(\delta \lambda_{m}^{2}+\delta \lambda_{m}+\delta+\lambda_{m}+1\right) \tau^{2}\right]\right.}\left.-2 h \phi\left(1+\lambda_{m}\right)\left(1+\lambda_{m}+\delta\right)\left(\delta \lambda_{m}^{2}+2 \delta \lambda_{m}+\lambda_{m}^{2}+2 \delta+3 \lambda_{m}+2\right)\right\} \\
& e_{\lambda_{m}}^{\phi, D *}=\frac{\left(\delta \lambda_{m}^{2}+\delta \lambda_{m}+\delta+\lambda_{m}+1\right)^{2}(a-c) \tau}{\left\{\left(\delta \lambda_{m}^{2}+\delta \lambda_{m}+\delta+\lambda_{m}+1\right)\left[2 h\left(\delta \lambda_{m}^{2}+2 \delta \lambda_{m}+\lambda_{m}^{2}+2 \delta+3 \lambda_{m}+2\right)-\left(\delta \lambda_{m}^{2}+\delta \lambda_{m}+\delta+\lambda_{m}+1\right) \tau^{2}\right]\right.} \\
&\left.-2 h \phi\left(1+\lambda_{m}\right)\left(1+\lambda_{m}+\delta\right)\left(\delta \lambda_{m}^{2}+2 \delta \lambda_{m}+\lambda_{m}^{2}+2 \delta+3 \lambda_{m}+2\right)\right\}
\end{aligned}
$$

From (32), (35), and (36), it follows that retail price is:

$$
p_{\lambda_{m}}^{\phi, D *}=c+\frac{h\left((\delta+2) \lambda_{m}^{2}+3 \delta\left(1+\lambda_{m}\right)+5 \lambda_{m}+3\right)\left(1+\lambda_{m}+\delta-\phi-\phi \delta \lambda_{m}-\phi \lambda_{m}^{2}+\delta \lambda_{m}^{2}-\phi \delta-2 \phi \lambda_{m}+\delta \lambda_{m}\right)(a-c)}{\left\{\left(\delta \lambda_{m}^{2}+\delta \lambda_{m}+\delta+\lambda_{m}+1\right)\left[2 h\left(\delta \lambda_{m}^{2}+2 \delta \lambda_{m}+\lambda_{m}^{2}+2 \delta+3 \lambda_{m}+2\right)-\left(\delta \lambda_{m}^{2}+\delta \lambda_{m}+\delta+\lambda_{m}+1\right) \tau^{2}\right]\right.}
$$

Thus, the manufacturer's profit, retailer's profit and the profit of the entire green supply chain are written, respectively:

$$
\begin{aligned}
& \bar{\pi}_{m, \lambda_{m}}^{\phi, D *}= \frac{1}{2\left(1+\lambda_{m}+\delta\right)\left[2\left(\lambda_{m}^{2}+(2+\delta) \lambda_{m}+1+\delta-A\right) C h+A^{2} \tau^{2}\right]^{2}}\left\{h\left[4 B C\left(A-\lambda_{m}^{2}-\left(2+\delta \lambda_{m}\right)-1-\delta\right)-2 B^{2} D\right] \times\right. \\
& {\left[2 \lambda_{m}^{4}+4(2+\delta) \lambda_{m}^{3}+\left(2 \delta^{2}+(12+D) \delta-D+12\right) \lambda_{m}^{2}+\left(4 \delta^{2}-D+12 \delta+8\right) \lambda_{m}+2(1+\delta)^{2}\right]+} \\
&\left.A^{4} \tau^{2}\left[(\phi-\delta) \lambda_{m}^{2}-((1-\phi) \delta+1-2 \phi) \lambda_{m}-(1+\delta)(1-\phi)\right]\right\} h(a-c)^{2} \\
& \bar{\pi}_{r, \lambda_{m}}^{\phi, D *}=\frac{h(a-c)^{2}\left[4\left(2 \lambda_{m}^{2}+2(2+\delta) \lambda_{m}+2(1+\delta)-D\right)\right]\left\{\left[\left(A-\lambda_{m}^{2}-(2+\delta) \lambda_{m}-1-\delta\right) C-B D / 2\right] B h+\phi A^{4} \tau^{2}\right\}}{2\left[2\left(\lambda_{m}^{2}+(2+\delta) \lambda_{m}+1+\delta-A\right) C h+A^{2} \tau^{2}\right]^{2}} \\
& \bar{\pi}_{S C, \lambda_{m}}^{\phi, D *}=\frac{h(a-c)^{2}\left\{\left[4 C\left(\lambda_{m}^{2}+(2+\delta) \lambda_{m}+1+\delta-A\right)+2 B D\right] B D h-A^{4} \tau^{2}\right\}}{2\left[2\left(\lambda_{m}^{2}+(2+\delta) \lambda_{m}+1+\delta-A\right) C h+A^{2} \tau^{2}\right]^{2}}
\end{aligned}
$$

where $A=\delta \lambda_{m}^{2}+\delta \lambda_{m}+\delta+\lambda_{m}+1, B=1+\lambda_{m}+\delta-\phi-\phi \delta \lambda_{m}-\phi \lambda_{m}^{2}+\delta \lambda_{m}^{2}-\phi \delta-2 \phi \lambda_{m}+\delta \lambda_{m}$, and $C=\delta \lambda_{m}^{2}+2 \delta \lambda_{m}+\lambda_{m}^{2}+2 \delta+3 \lambda_{m}+2, D=(\delta+2) \lambda_{m}^{2}+3 \delta\left(1+\lambda_{m}\right)+5 \lambda_{m}+3$. 
Proposition 5. For the green supply chain with a loss-averse manufacturer and a greening cost-sharing contract, the optimal proportion of greening cost shared by retailer shares with manufacturer is:

$$
\phi_{\lambda_{m}}^{*}=\frac{2 h\left(1+\lambda_{m}\right)\left(1+\lambda_{m}+\delta\right)\left(\delta \lambda_{m}^{2}+\delta \lambda_{m}+\lambda_{m}+\delta+1\right)-\left(\delta \lambda_{m}^{2}+\delta \lambda_{m}+\lambda_{m}+\delta+1\right)^{2}\left(2 h-\tau^{2}\right)}{2\left(1+\lambda_{m}\right)\left(1+\lambda_{m}+\delta\right)\left(\delta \lambda_{m}^{2}+4 \delta \lambda_{m}+3 \lambda_{m}^{2}+4 \delta+7 \lambda_{m}+4\right) h} .
$$

Proof. See Appendix F.

Proposition 6. For the green supply chain with a loss-averse manufacturer and a greening cost-sharing contract, if the probability of breakdown about bargaining game tends to zero (i.e., $\delta \rightarrow 1$ ), then we distinguish two cases:

Case (i) $\tau^{2} / h \geq 8 / 7$. Then, $\phi_{\lambda_{m}}^{*}<\phi^{*}$.

Case (ii) $\tau^{2} / h<8 / 7$. Then, there are three subcases:

Subcase (i) $\phi_{\lambda_{m}}^{*}>\phi^{*}$ if $\lambda_{m}^{2}+2 \lambda_{m}+2>\left(3 \tau^{2} / h\right) /\left(8-7 \tau^{2} / h\right)$.

Subcase (ii) $\phi_{\lambda_{m}}^{*}<\phi^{*}$ if $\lambda_{m}^{2}+2 \lambda_{m}+2<\left(3 \tau^{2} / h\right) /\left(8-7 \tau^{2} / h\right)$.

Subcase (iii) $\phi_{\lambda_{m}}^{*}=\phi^{*}$ if $\lambda_{m}^{2}+2 \lambda_{m}+2=\left(3 \tau^{2} / h\right) /\left(8-7 \tau^{2} / h\right)$.

Proof. See Appendix G.

Remark 5. Proposition 5 shows that the retailer shares the optimal proportion of greening cost with the loss-averse manufacturer. Based on Proposition 6, when the probability of breakdown about the bargaining game tends to zero, if the green efficiency coefficient is high (i.e., $\tau^{2} / h \geq 8 / 7$ ), then the optimal proportion of greening cost that the retailer shares with the loss-averse manufacturer is lower than the optimal proportion of greening cost that the retailer shares with a risk-neutral manufacturer. When the green efficiency coefficient is high, the consumers prefer to purchase green products because of the consumer environmental awareness. In this case, green degree has a critical impact on demand of products. Retail price and green degree in DDS-LAM are lower than those in the DSS (see Propositions 2 and 3), which implies that the retailer prefers to share a low proportion of greening cost with a loss-averse manufacturer compared to the case in which the manufacturer is risk-neutral. On the other hand, for the case where the green efficiency coefficient is low (i.e., $\tau^{2} / h<8 / 7$ ), if the loss-aversion coefficient of the manufacturer is sufficiently high (low), then the proportion of greening cost shared by the retailer is higher (lower) than the proportion that the retailer shares with a risk-neutral manufacturer. In this case, green degree has little effect on demand of products. If the loss-aversion level of the manufacturer is sufficiently high, to encourage the manufacturer to produce green products, the retailer is willing to share a high proportion of greening cost with a loss-averse manufacturer. If the loss-aversion level of the manufacturer is sufficiently low, then the retailer prefers to share a low proportion of greening cost with a loss-averse manufacturer since loss aversion hurts retailer's profit.

\section{Numerical Analysis}

To show the impact of loss-aversion coefficient and the green efficiency coefficient on wholesale price, numerical examples are used, where $a=120, c=20, \lambda_{m}=2$, and $\delta=0.4$.

Figure 2 presents the changes of wholesale price with the green efficiency coefficient in the two decision-making settings (i.e., DDS and DDS-LAM). In Figure 2, if $0<\tau^{2} / h<2$, then wholesale price in DDS is lower than that in DDS-MLA. In Figure 3, if $\tau^{2} / h=0.5$, then wholesale price in DSS-MLA is increasing in $\lambda_{m}$ and is higher than that in DSS. That is, the loss-averse manufacturer sells products at a high wholesale price if the green efficiency coefficient of products is sufficiently low, since a low green efficiency coefficient of products cannot result in a significant increase in market demand, which causes the loss-averse manufacturer to sell products at a high wholesale price to obtain profit, and a higher loss aversion leads to a higher wholesale price.. If $2<\tau^{2} / h<4$, then wholesale price in the 
DDS is higher than that in DDS-MLA. In Figure 3, if $\tau^{2} / h=2.5$, then wholesale price in DSS-MLA is decreasing in $\lambda_{m}$ and is lower than that in DSS. That is, the loss-averse manufacturer sells products at a low wholesale price if the green efficiency coefficient of products is sufficiently high, since a high green efficiency coefficient of products results in a significant increase in market demand, which causes the loss-averse manufacturer to sell products at a high wholesale price to obtain profit. In this case, the risk-neutral retailer sells products at a low, but the risk-neutral retailer obtains a large profit by quick turnover, which causes the loss-averse manufacturer to sell products at a low wholesale price to obtain profit, and a higher loss aversion leads to a lower wholesale price. If $\tau^{2} / h=2$, wholesale price has no difference in the two decision-making settings. In addition, wholesale price increases with the green efficiency coefficient of products $\tau^{2} / h$.

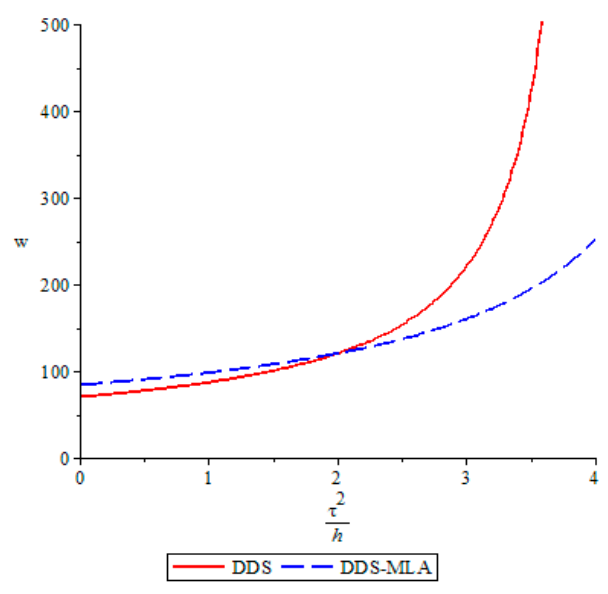

Figure 2. The impact of green efficiency coefficient on wholesale price.

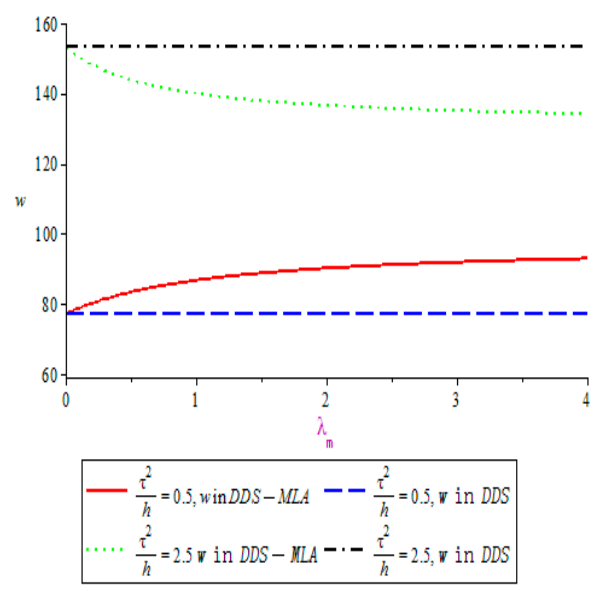

Figure 3. The impact of loss-aversion coefficient on wholesale price.

We use numerical examples to analyze retail price with respect to the loss-aversion coefficient and the green efficiency coefficient. Let $a=120, c=20, \lambda_{m}=2$, and $\delta=0.4$.

In Figure 4 , if $0<\tau^{2} / h<1$, then retail price in CDS is lower than that in DDS, while the latter is lower than retail price in DDS-LAM. If $1<\tau^{2} / h<2$, then retail price in the CDS is higher than that in DDS, while the latter is higher than retail price in DDS-LAM. If $\tau^{2} / h=1$, retail price has no difference in the three decision-making settings. In addition, retail price in the three decision-making settings increases with the green efficiency coefficient of products $\tau^{2} / h$. The green efficiency coefficient has an important impact on retail price. In Figure 5 , if $\tau^{2} / h=0.5$, then retail price in DSS-MLA is increasing in $\lambda_{m}$. If $\tau^{2} / h=2.5$, then retail price in DSS-MLA is decreasing in $\lambda_{m}$. From Figures 3 and 5 , it follows that wholesale price and retail price increase with $\lambda_{m}$ if the green efficiency coefficient of products is at a lower level (i.e., $\tau^{2} / h=0.5$ ), while wholesale price and retail price decrease with $\lambda_{m}$ if 
the green efficiency coefficient of products is at a higher level (i.e., $\tau^{2} / h=2.5$ ). In other words, for the case where the green efficiency coefficient of products is lower (i.e., the consumer sensitivity to green improvements is lower or the cost coefficient of green degree per unit is higher), the manufacturer with loss aversion can make up for the cost incurred (i.e., losses), which is used to invest in the new equipment or technology, by increasing wholesale price. On the other hand, the retailer increases retail price to improve his profit, since lower sensitivity to green degree leads to a lower market demand for green products. For the case where the green efficiency coefficient of products is higher (i.e., the consumer sensitivity to green improvements is higher or the cost coefficient of green degree per unit is lower), a higher level of consumer sensitivity to green improvements leads to increasing heavily market demand for green products. The manufacturer with loss aversion decreases wholesale price to increase sales such that the manufacturer improves his profit, while the retailer decreases retail price to sell more products such that the retailer increases his profit.

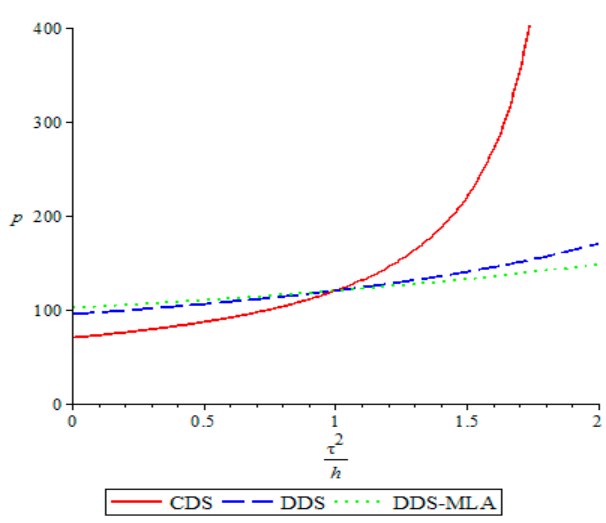

Figure 4. The impact of green efficiency coefficient on retail price.

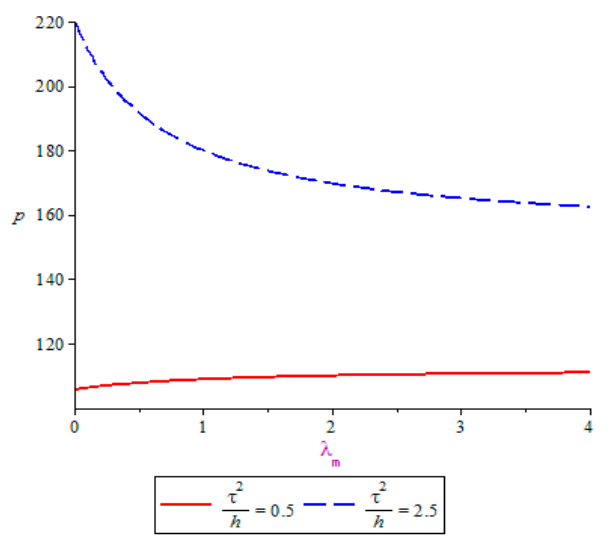

Figure 5. The impact of loss-aversion coefficient on retail price.

To explore the impact of the loss-aversion coefficient and the green efficiency coefficient on green degree, numerical examples are used, where $a=120, c=20, \lambda_{m}=2$, and $\delta=0.4$.

In Figure 6, green degree in the three decision-making settings increases with the green efficiency coefficient of products $\tau^{2} / h$. Green degree in CDS is the highest in the three decision-making settings, while green degree in DDS-LAM is the lowest in the three decision-making settings. Furthermore, green degree in the three decision-making settings increases with $\tau^{2} / h$. Green degree in CDS is the highest in the three decision-making settings, while green degree in DDS-LAM is the lowest. The change of green degree with the loss-aversion coefficient is shown in Figure 7. A higher level of consumer sensitivity to green improvements leads to increasing heavily market demand for green products. Thus, the manufacturer is more motivated to invest in new equipment or technology to produce green products such that the manufacturer increases his profit. On the other hand, green 
degree decreases with the loss-aversion coefficient $\lambda_{m}$. The manufacturer with loss aversion pays more attention to gains or losses than to profits. Investing in new equipment or technology decreases the manufacturer's profit. Thus, the higher the manufacturer's degree of loss aversion is, the lower the probability of producing green products is. This implies that a higher level of loss aversion leads to a lower green degree of products.

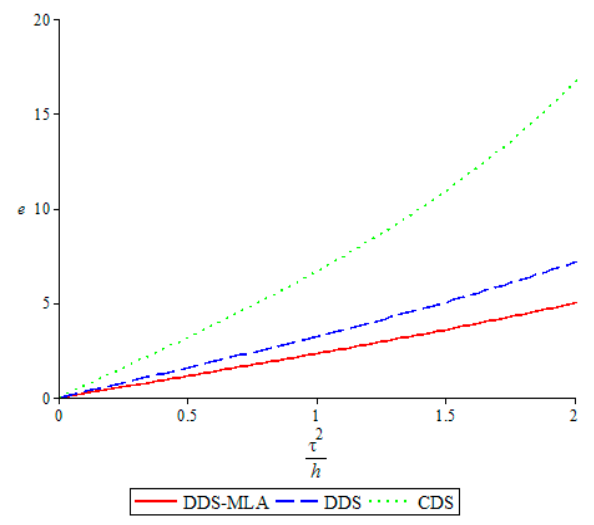

Figure 6. The impact of green efficiency coefficient on green degree.

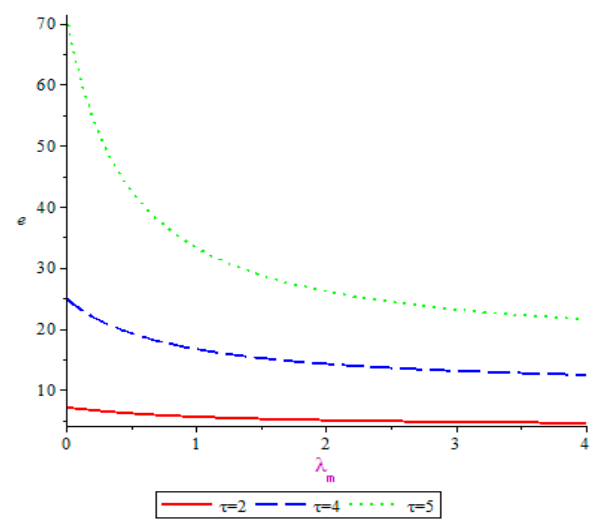

Figure 7. The impact of loss-aversion coefficient on green degree.

Figure 8 shows the changes of with the profit of green supply chain with green efficiency coefficient. Figure 9 shows the changes of profits of manufacturer and retailer with loss-aversion coefficient. In Figure 8, the profit of the entire green supply chain in CDS is higher than that in DDS, while the latter is higher than the profit of the entire green supply chain in DDS-LAM. Note that the profit of the entire green supply chain in the three decision-making settings increases with $\tau^{2} / h$. The profit of the entire green supply chain in CDS is the highest in the three decision-making settings, while the profit of the entire green supply chain in DDS-LAM is the lowest. In other words, the efficiency of the green supply chain in CDS (DDS-LAM) is the highest (lowest) in the three decision-making settings. In Figure 9, manufacturer's profit in DDS-LAM is lower than that in DDS. A similar conclusion holds for the retailer. In addition, manufacturer's profit and retailer's profit decrease with manufacturer's levels of loss aversion. This implies that a loss-averse manufacturer is willing to sacrifice part of his own profit and take actions to punish the retailer such that the manufacturer maintain the gains relative to the reference point.

To explore the impact of the proportion of greening cost shared by the retailer on profits of manufacturer and retailer, numerical examples are used, where $a=120, c=20, \lambda_{m}=2, \delta=0.4, h=4$, and $\tau=10$. In Figure 10, after executing a greening cost-sharing contract, the profits of manufacturer and retailer are first increasing and then decreasing with $\varphi$. From Figure 10, it follows that executing the greening cost-sharing contract can improve the profits of manufacturer and retailer if an appropriate 
proportion of greening cost is shared by the retailer. That is, a greening cost-sharing contract can boost the manufacturer to manufacture green products if the retailer shares an appropriate proportion of greening cost with the manufacturer.

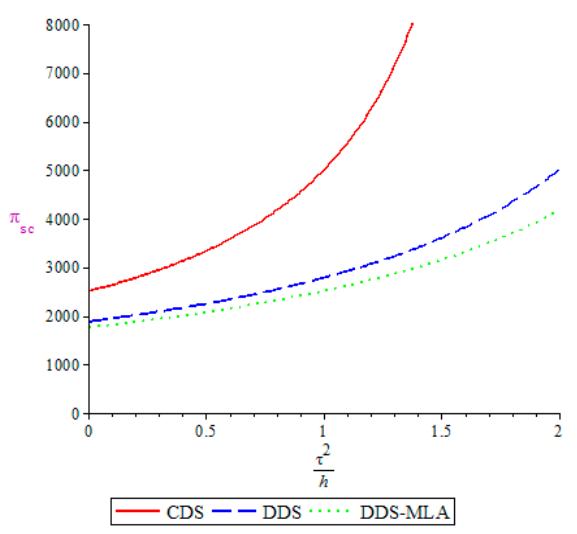

Figure 8. The impact of green efficiency coefficient on profit of green supply chain.

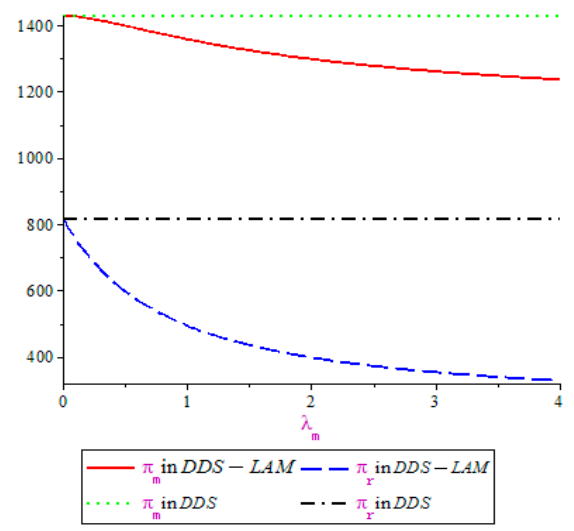

Figure 9. The impact of loss-aversion coefficient on manufacturer's profit and retailer's profit.

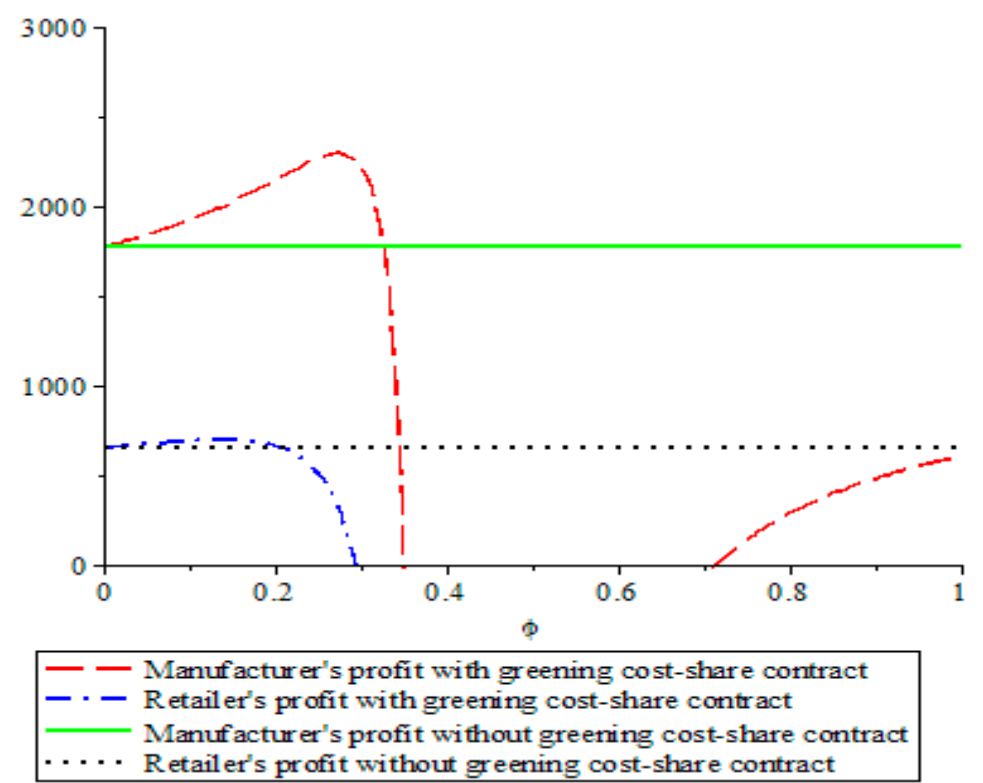

Figure 10. The impact of the proportion of greening cost on profits of manufacturer and retailer. 


\section{Summary}

\subsection{Managerial Insights}

This study can be applied to the green supply chain where the manufacturer occupies an absolute dominant position in the green supply chain. For example, the mobile phone industry supply chain includes HUAWEI, APPLE, and SAMSUNG. The model constructed in this paper helps non-rational decision-makers to make the optimal decisions in the green supply chains. In particular, in this paper, the model helps the loss-aversion manufacturer to make the optimal wholesale price decision and the optimal green degree decision. In addition, the model helps the risk-neutral retailer to make the optimal retail price decision. Thus, our model is of important theoretical and practical significance. On the one hand, this model promotes further theoretical study of green supply chains by considering a two-echelon green supply chain with a manufacturer and a retailer, where the manufacturer is loss-averse and the retailer is risk-neutral. On the other hand, this model helps the loss-aversion manufacturer and the risk-neutral retailer to make the optimal decisions in the green supply chains by providing some useful managerial insights into how to make pricing, green degree and coordination decisions. First, if the green efficiency coefficient of products is sufficiently low, then the risk-neutral retailer prefers to make a high retail price and the loss-aversion manufacturer sells products at a high wholesale price, since in the green supply chains market demand depends on retail price and green degree of products and a lower green efficiency coefficient of products cannot result in a significant increase in market demand, which makes the risk-neutral retailer and the loss-aversion manufacturer set a high retail price and a high wholesale price to obtain profits, respectively. In addition, if the green efficiency coefficient of products is sufficiently high, then the risk-neutral retailer prefers to make a low retail price and the loss-aversion manufacturer sells products at a low wholesale price, since a higher level of environmental awareness causes consumers to purchase higher-green-degree products when the green efficiency coefficient of products is sufficiently high, which results in dramatically increasing market demand. In this case, the risk-neutral retailer sells products at a low price, but the risk-neutral retailer obtains a large profit by quick turnover, which causes the loss-averse manufacturer sells products at a low wholesale price. Second, the loss-aversion manufacturer will make a low green degree, since the manufacturer with loss aversion is not willing to invest in new equipment or technology to produce the green products. Finally, a greening cost-sharing contract can improve the efficiency of green supply chain if the retailer shares an appropriate proportion of greening cost with the manufacturer. In this case, executing a greening cost-sharing contract can improve the profits of the loss-aversion manufacturer and the risk-neutral retailer, which results in the loss-aversion manufacturer and the risk-neutral retailer preferring to execute the greening cost-sharing contract. It is worthwhile to note that members of green supply chains have to consider the green efficiency coefficient of products to apply our model, since the green efficiency coefficient of products has an important impact on the optimal wholesale price decision, the optimal green degree decision, and the retail price decision.

\subsection{Concluding Remarks}

In this paper, the manufacturer's behavioral preference of loss aversion is formalized by Shalev's model of loss aversion, where the subgame perfect equilibrium partition is regarded as a reference point of loss aversion. We investigate the impacts of loss aversion and green efficiency coefficient on retail price, wholesale price, green degree, profits of members, and the profit of the entire green supply chain under three decision-making settings (i.e., the CDS, DDS, and DDS-LAM). Furthermore, to achieve coordination of green supply chain with a loss-averse manufacturer and a risk-neutral retailer, we discuss the greening cost-sharing contract.

The green efficiency coefficient has an important effect on wholesale price, retail price and green degree. The manufacturer's loss aversion leads to a low wholesale price if the green efficiency coefficient is sufficiently high, or wholesale price in DDS-LAM is not less than that in DDS. If the 
green efficiency coefficient is sufficiently high, then retail price in CDS is higher than that in DDS, which is a reversed result of the traditional supply chains. The manufacturer's loss aversion further decreases retail price, which means that retail price is the lowest in DDS-LAM, followed by DDS, while it is the highest in CDS. When it comes to the green degree, the green degree is the lowest in DDS-LAM, followed by DDS, while it is the highest in CDS regardless of the green efficiency coefficient. In addition, wholesale price and retail price decrease (increase) with the manufacturer's level of loss aversion if the green efficiency coefficient is sufficiently high (low) and green degree decreases with the manufacturer's level of loss aversion, as shown in numerical analysis.

Moreover, for the manufacturer, the manufacturer's loss aversion leads to the low profit. Compared with the risk-neutral manufacturer, the manufacturer is hurt by his own loss aversion. For retailer, the profit in DDS-LAM is lower than that in DDS. Retailer is also hurt by the manufacturer's loss aversion. These further decrease the profit of the green supply chain. Thus, the profit of the entire green supply chain is the highest in CDS, followed by DDS, while it is the lowest in DDS-LAM. In addition, in DDS-LAM, profits of chain members decrease with the manufacturer's level of loss aversion, as shown in numerical analysis.

Finally, the coordination of the green supply chain with a loss-averse manufacturer and a risk-neutral retailer can be achievable by executing a green cost-sharing contract if the retailer shares an appropriate proportion with the loss-averse manufacturer.

This paper considers a green supply chain with a loss-averse manufacturer and a risk-neutral retailer. It is interesting to extend our study to incorporate the governmental interventions, since facing with the deteriorating environment governments pay increasing attention to environmental issues and promulgate a series of policy on environmental protection, especially the environmental awareness of enterprises. Moreover, considering the impact of loss aversion in the competition among multiple manufacturers or multiple retailers would be another rewarding issue.

Author Contributions: Both authors contributed equally in the writing of this article.

Funding: This work was partly supported by the National Natural Science Foundation of China (Nos. 71671188 and 71874112), Beijing Intelligent Logistics System Collaborative Innovation Center (BILSCIC-2018KF-04), and the Natural Science Foundation of Hunan Province, China (2016JJ1024).

Conflicts of Interest: The authors declare no conflicts of interest.

\section{Appendix A. Proof of Lemma 1}

To derive the loss-averse reference point for the manufacturer, the bargaining structure between the loss-averse manufacturer and the risk-neutral retailer is described as follows.

The manufacturer and the retailer bargain over the profit of the entire green supply chain $\pi_{s c}$. Proposals are made at times $t \in T:=\{1,2, \ldots\}$. At times $t \in T_{\text {odd }}:=\{1,3, \ldots\}$, the manufacturer makes a proposal, and the retailer decides to accept or reject this proposal. At times $t \in T_{\text {even }}:=\{2$, $4, \ldots\}$, the roles of the manufacturer and the retailer are reversed. For a proposal $\pi^{\prime}=\left(\pi_{m}^{\prime}, \pi_{r}^{\prime}\right)$ in which $\pi_{m}^{\prime}+\pi_{r}^{\prime}=\pi_{s c}$ is accepted, then the bargaining ends and the manufacturer and the retailer obtain $\pi_{m}^{\prime}$ and $\pi_{r}^{\prime}$, respectively. Let $\delta$ be denoted by a discount factor. If a proposal is rejected, then the bargaining continues to the next time with the probability $\delta$ and stops with the probability $1-\delta$ [24]. If the bargaining perpetually disagrees, then both members obtain the share zero.

To incorporate manufacturer's preference of loss aversion into the bargaining game, suppose that the manufacturer and the retailer reach agreement on a proposal $\pi=\left(\pi_{m}, \pi_{r}\right)$ at some time $t \in T$, where $\pi_{m}+\pi_{r}=\pi_{s c}$, then the manufacturer and the retailer obtain $\pi_{m}$ and $\pi_{r}$, respectively. Let $v_{m}$ be the manufacturer's reference point and let $\lambda_{m}(\geq 0)$ be the loss-aversion coefficient of the manufacturer. It follows from (15) that:

$$
u_{m}=\left(1+\lambda_{m}\right) \pi_{m}-\lambda_{m} \max \left\{v_{m}, \pi_{m}\right\} .
$$

The reference point $v_{m}$ is determined endogenously in the following way. At some time $t \in T$, considering all the proposals made to the manufacturer by the retailer so far, these represent all the 
shares that the manufacturer could have obtained up to this time with certainty. Thus, a natural assumption is that the maximum of these shares is regarded as the reference point of the manufacturer. The shares below the reference point are regarded as losses, and their utility values are evaluated by (A1). We assume that the initial reference point for the manufacturer is equal to zero, which means that the manufacturer does not produce products. If $\pi^{1}, \pi^{2}, \ldots, \pi^{t}$ are the offers up to time $t$, where $\pi^{j}=\left(\pi_{m}^{j}, \pi_{r}^{j}\right)$ for $j \leq t$, then the manufacturer's reference point is $v_{m}^{t}=\max \left\{0, \pi_{m}^{j} \mid j=2,4, \ldots \leq t\right\}$.

To determine the reference point, a subgame perfect equilibrium has to be constructed, which follows the idea that manufacturer's (or retailer's) offer should make the retailer (manufacturer) indifferent between this offer and the offer of retailer (manufacturer) himself in the next time. At some time $t \in T_{o d d}$, where the manufacturer makes a proposal $\pi^{\prime}=\left(\pi_{m}^{\prime}, \pi_{r}^{\prime}\right)$, suppose that the retailer makes a proposal $\pi^{\prime \prime}=\left(\pi_{m}^{\prime \prime}, \pi_{r}^{\prime \prime}\right)$ at time $t+1$ after rejection. To make the retailer accept the proposal of the manufacturer, we would need:

$$
\pi_{r}^{\prime} \geq \delta \pi_{r}^{\prime \prime}
$$

At some time $t \in T_{\text {even, }}$, where the retailer makes a proposal $\pi^{\prime \prime}=\left(\pi_{m}^{\prime \prime}, \pi_{r}^{\prime \prime}\right)$, the manufacturer offers $\pi^{\prime}=\left(\pi_{m}^{\prime}, \pi_{r}^{\prime}\right)$ at the next time after rejection. Let $v_{m}$ be manufacturer's reference point at time $t-1$ (so $v_{m}=0$ at time $t=0$ ). To make the manufacturer accept the proposal of the retailer, we would need:

$$
\left(1+\lambda_{m}\right) \pi_{m}^{\prime \prime}-\lambda_{m} \max \left\{\pi_{m}^{\prime \prime}, v_{m}\right\} \geq \delta\left[\left(1+\lambda_{m}\right) \pi_{m}^{\prime}-\lambda_{m} \max \left\{\pi_{m}^{\prime}, \max \left\{\pi_{m}^{\prime \prime}, v_{m}\right\}\right\}\right]-(1-\delta) \lambda_{m} \max \left\{\pi_{m}^{\prime \prime}, v_{m}\right\}
$$

To construct a subgame perfect equilibrium, we assume that inequalities (A2) and (A3) are equalities. Then, elaborating (A2) with equality yields: $I . \delta \pi_{r}^{\prime \prime}=\pi_{r}^{\prime}$.

Elaborating (A3) with equality yields the following cases:

(1) $v_{m}>\pi_{m}^{\prime}>\pi_{m}^{\prime \prime}: \delta \pi_{m}^{\prime}=\pi_{m}^{\prime \prime}$;

(2) $\pi_{m}^{\prime} \geq v_{m}>\pi_{m}^{\prime \prime}: \delta \pi_{m}^{\prime}=\left(1+\lambda_{m}\right) \pi_{m}^{\prime \prime}-\delta \lambda_{m} v_{m} ;$

(3) $\pi_{m}^{\prime}>\pi_{m}^{\prime \prime} \geq v_{m}: \delta \pi_{m}^{\prime}=\left(1+\lambda_{m}(1-\delta)\right) \pi_{m}^{\prime \prime}$.

By combining these equalities, we obtain the following three sets and corresponding equilibrium proposals.

- Region 1, I

$$
X_{1, I}=\left\{v_{m}, v_{m} \in[0,1] \mid v_{m}>\frac{\pi_{s c}}{1+\delta}\right\}
$$

The equilibrium in $X_{1, I}$ is:

$$
\pi^{\prime 1, I}=\left(\frac{\pi_{s c}}{1+\delta}, \frac{\delta \pi_{S C}}{1+\delta}\right), \pi^{\prime \prime 1}, I=\left(\frac{\delta \pi_{S C}}{1+\delta}, \frac{\pi_{S C}}{1+\delta}\right)
$$

- Region 1, II

$$
X_{2, I}=\left\{v_{m}, v_{m} \in[0,1] \mid \frac{\delta(1-\delta) \pi_{s c}+\delta \lambda_{m} v_{m}}{1+\lambda_{m}-\delta^{2}}<v_{m} \leq \frac{\pi_{s c}}{1+\delta}\right\} .
$$

The equilibrium in $X_{1, I I}$ is:

$$
\begin{gathered}
\pi^{\prime 2, I}=\left(\frac{\left(1+\lambda_{m}\right)(1-\delta) \pi_{s c}+\delta^{2} \lambda_{m} v_{m}}{1+\lambda_{m}-\delta^{2}}, \frac{\delta\left(1+\lambda_{m}\right)(1-\delta) \pi_{s c}+\delta^{2} \lambda_{m}\left(\pi_{s c}-v_{m}\right)}{1+\lambda_{m}-\delta^{2}}\right) ; \\
\pi^{\prime \prime 2, I}=\left(\frac{\delta(1-\delta) \pi_{s c}+\delta \lambda_{m} v_{m}}{1+\lambda_{m}-\delta^{2}}, \frac{\left(1+\lambda_{m}\right)(1-\delta) \pi_{s c}+\delta \lambda_{m}\left(\pi_{s c}-v_{m}\right)}{1+\lambda_{m}-\delta^{2}}\right) .
\end{gathered}
$$

- Region 1, III

$$
X_{3, I}=\left\{v_{m}, v_{m} \in[0,1] \mid v_{m} \leq \frac{\delta \pi_{s c}}{1+\lambda_{m}+\delta}\right\}
$$


The equilibrium in $X_{1, \text { III }}$ is:

$$
\pi^{\prime 3, I}=\left(\frac{\left(1+\lambda_{m}(1-\delta)\right) \pi_{s c}}{1+\lambda_{m}+\delta}, \frac{\delta\left(1+\lambda_{m}\right) \pi_{s c}}{1+\lambda_{m}+\delta}\right) ; \pi^{\prime \prime 3, I}=\left(\frac{\delta \pi_{s c}}{1+\lambda_{m}+\delta}, \frac{\left(1+\lambda_{m}\right) \pi_{s c}}{1+\lambda_{m}+\delta}\right) .
$$

In the set $X_{1, I}$, the equilibrium outcome obtained in $X_{1, I}$ is identical to that in the classical Rubinstein case where the manufacturer and the retailer are risk-neutral. Thus, the equilibrium partition in $X_{1, I}$ cannot be regarded as the reference point of the loss-averse manufacturer. In the set $X_{1, I I}$, the equilibrium outcome depends on the reference point $v_{m}$, which means that the equilibrium outcome is not unique. Thus, it is inappropriate for the equilibrium partition in $X_{1, I I}$ to be regarded as the reference point. It is easy to prove the uniqueness of the equilibrium partition in $X_{1, I I I}$, since the equilibrium partition in $X_{1, I I}$ depends on the loss-aversion coefficient, but not on $v_{m}$. The bargaining outcome is:

$$
\pi^{\prime 3, I}=\left(\frac{\left(1+\lambda_{m}(1-\delta)\right) \pi_{s c}}{1+\lambda_{m}+\delta}, \frac{\delta\left(1+\lambda_{m}\right) \pi_{s c}}{1+\lambda_{m}+\delta}\right) .
$$

Thus, the manufacturer's reference point is:

$$
v_{m}^{*}=\frac{\left(1+\lambda_{m}(1-\delta)\right) \pi_{s c}}{1+\lambda_{m}+\delta}
$$

\section{Appendix B. Proof of Proposition 1}

It follows from (10) and (21) that:

$$
\begin{aligned}
w_{\lambda_{m}}^{D *}-w_{D}^{*} & =\frac{2 h \lambda_{m}\left(1+\lambda_{m}(1-\delta)\right)\left(2 h-\tau^{2}\right)(a-c)}{\left[\left(1+\lambda_{m}\right)(1+\delta)\left(4 h-\tau^{2}\right)+\delta \lambda_{m}^{2}\left(2 h-\tau^{2}\right)+2 h \lambda_{m}\left(1+\lambda_{m}\right)\right]\left(4 h-\tau^{2}\right)} \\
& =\frac{2 \lambda_{m}\left(1+\lambda_{m}(1-\delta)\right)\left(2-\tau^{2} / h\right)(a-c)}{\left[\left(1+\lambda_{m}\right)(1+\delta)\left(4-\tau^{2} / h\right)+\delta \lambda_{m}^{2}\left(2-\tau^{2} / h\right)+2 \lambda_{m}\left(1+\lambda_{m}\right)\right]\left(4-\tau^{2} / h\right)} .
\end{aligned}
$$

In Section 3.1.2, we have $0<\tau^{2} / h<4$. Thus, we have the following three cases:

- $\quad 0<\tau^{2} / h<2$. In this case, we have $w_{\lambda_{m}}^{D *}>w_{D}^{*}$.

- $\quad \tau^{2} / h=2$. In this case, we have $w_{\lambda_{m}}^{D *}=w_{D}^{*}$.

- $\quad 2<\tau^{2} / h<4$. In this case, we have $w_{\lambda_{m}}^{D *}<w_{D}^{*}$.

\section{Appendix C. Proof of Proposition 2}

It follows from (11) and (23) that:

$$
\begin{aligned}
p_{\lambda_{m}}^{D *}-p_{D}^{*} & =\frac{2 h\left(1+\lambda_{m}(1-\delta)\right)\left(h-\tau^{2}\right)(a-c)}{\left[\left(1+\lambda_{m}\right)(1+\delta)\left(4 h-\tau^{2}\right)+\delta \lambda_{m}^{2}\left(2 h-\tau^{2}\right)+2 h \lambda_{m}\left(1+\lambda_{m}\right)\right]\left(4 h-\tau^{2}\right)} \\
& =\frac{2\left(1+\lambda_{m}(1-\delta)\right)\left(1-\tau^{2} / h\right)(a-c)}{\left[\left(1+\lambda_{m}\right)(1+\delta)\left(4-\tau^{2} / h\right)+\delta \lambda_{m}^{2}\left(2-\tau^{2} / h\right)+2 \lambda_{m}\left(1+\lambda_{m}\right)\right]\left(4 h-\tau^{2} / h\right)} .
\end{aligned}
$$

It follows from (6) and (11) that:

$$
p_{D}^{*}-p^{*}=\frac{2 h(a-c)\left(h-\tau^{2}\right)}{\left(2 h-\tau^{2}\right)\left(4 h-\tau^{2}\right)}=\frac{2(a-c)\left(1-\tau^{2} / h\right)}{\left(2-\tau^{2} / h\right)\left(4-\tau^{2} / h\right)} .
$$

In Section 3.1.1, we have $0<\tau^{2} / h<2$. Thus, the following three cases are shown as:

- $\quad 0<\tau^{2} / h<1$. In this case, we have $p_{\lambda_{m}}^{D *}>p_{D}^{*}>p^{*}$.

- $\tau^{2} / h=1$. In this case, we have $p_{\lambda_{m}}^{D *}=p_{D}^{*}=p^{*}$.

- $\quad 1<\tau^{2} / h<2$. In this case, we have $p_{\lambda_{m}}^{D *}<p_{D}^{*}<p^{*}$. 


\section{Appendix D. Proof of Proposition 3}

It follows from (10) and (22) that:

$$
\begin{aligned}
e_{\lambda_{m}}^{D *}-e^{D *} & =-\frac{2\left(\tau^{2} / h\right) \lambda_{m}\left(1+\lambda_{m}(1-\delta)(a-c)\right.}{\left[\left(1+\lambda_{m}\right)(1+\delta)\left(4-\tau^{2} / h\right)+\delta \lambda_{m}^{2}\left(2-\tau^{2} / h\right)+2 \lambda_{m}\left(1+\lambda_{m}\right)\right]\left(4-\tau^{2} / h\right)} \\
& =-\frac{2 \tau^{2} / h \lambda_{m}\left(1+\lambda_{m}(1-\delta)(a-c)\right.}{\left[\left(1+\lambda_{m}\right)(1+\delta)\left(4-\tau^{2} / h\right)+\delta \lambda_{m}^{2}\left(2-\tau^{2} / h\right)+2 \lambda_{m}\left(1+\lambda_{m}\right)\right]\left(4-\tau^{2} / h\right)}
\end{aligned}
$$

It follows from (6) and (10) that:

$$
e^{D *}-e^{*}=-\frac{2 \tau^{2} h(a-c)}{\left(4 h-\tau^{2}\right)\left(2 h-\tau^{2}\right)}=-\frac{2 \tau^{2} / h(a-c)}{\left(4-\tau^{2} / h\right)\left(2-\tau^{2} / h\right)} .
$$

In Section 3.1.1, we have $0<\tau^{2} / h<2$. Thus, we have $e_{\lambda_{m}}^{D *}<e^{D *}<e^{*}$.

\section{Appendix E. Proof of Proposition 4}

For case (i), it follows from (12) and (24) that:

$$
\begin{aligned}
& \pi_{m, \lambda_{m}}^{D *}-\pi_{m}^{D}=-\frac{2 h^{3} \lambda_{m}^{2}\left(1+\lambda_{m}(1-\delta)\right)^{2}(a-c)^{2}}{2\left[\left(1+\lambda_{m}\right)(1+\delta)\left(4 h-\tau^{2}\right)+\lambda_{m}^{2} \delta\left(2 h-\tau^{2}\right)+2 h \lambda_{m}\left(1+\lambda_{m}\right)\right]^{2}\left(4 h-\tau^{2}\right)} \\
&=-\frac{\left(\left(1+\lambda_{m}+\delta\right)\left(\left(1+\lambda_{m}\right)(1+\delta)\left(4 h-\tau^{2}\right)+\lambda_{m}^{2} \delta\left(2 h-\tau^{2}\right)+2 h \lambda_{m}\left(1+\lambda_{m}\right)\right)\right)}{2\left[\left(1+\lambda_{m}\right)(1+\delta)\left(4-\tau^{2} / h\right)+\lambda_{m}^{2} \delta\left(2-\tau^{2} / h\right)+2 \lambda_{m}\left(1+\lambda_{m}\right)\right]^{2}\left(4-\tau^{2} / h\right)}
\end{aligned}
$$

In Section 3.1.2, we have $0<\tau^{2} / h<4$. Thus, we have $\pi_{m, \lambda_{m}}^{D *}<\pi_{m}^{D}$.

For case (ii), it follows from (13) and (25) that:

$$
\begin{aligned}
\pi_{r, \lambda_{m}}^{D *}-\pi_{r}^{D} & =-\frac{4 h^{3} \lambda_{m}\left(1+\lambda_{m}(1-\delta)\right)\left[\lambda_{m}^{2} \delta\left(2 h-\tau^{2}\right)+\left(1+\lambda_{m}\right)(1+\delta)\left(4 h-\tau^{2}\right)+h \lambda_{m}\left(1+\lambda_{m}+\delta \lambda_{m}\right)\right](a-c)^{2}}{\left[\left(1+\lambda_{m}\right)(1+\delta)\left(4 h-\tau^{2}\right)+\lambda_{m}^{2} \delta\left(2 h-\tau^{2}\right)+2 h \lambda_{m}\left(1+\lambda_{m}\right)\right]^{2}\left(4 h-\tau^{2}\right)^{2}} \\
& =-\frac{4 \lambda_{m}\left(1+\lambda_{m}(1-\delta)\right)\left[\lambda_{m}^{2} \delta\left(2-\tau^{2} / h\right)+\left(1+\lambda_{m}\right)(1+\delta)\left(4-\tau^{2} / h\right)+\lambda_{m}\left(1+\lambda_{m}+\delta \lambda_{m}\right)\right](a-c)^{2}}{\left[\left(1+\lambda_{m}\right)(1+\delta)\left(4-\tau^{2} / h\right)+\lambda_{m}^{2} \delta\left(2-\tau^{2} / h\right)+2 \lambda_{m}\left(1+\lambda_{m}\right)\right]^{2}\left(4-\tau^{2} / h\right)^{2}} \\
& =-\frac{4 \lambda_{m}\left(1+\lambda_{m}(1-\delta)\right)\left[\lambda_{m}^{2} \delta\left(3-\tau^{2} / h\right)+\lambda_{m}^{2}+\left(1+\lambda_{m}\right)(1+\delta)\left(4-\tau^{2} / h\right)+\lambda_{m}\right](a-c)^{2}}{\left[\left(1+\lambda_{m}\right)(1+\delta)\left(4-\tau^{2} / h\right)+\lambda_{m}^{2} \delta\left(2-\tau^{2} / h\right)+2 \lambda_{m}\left(1+\lambda_{m}\right)\right]^{2}\left(4-\tau^{2} / h\right)^{2}} \\
& <-\frac{4 \lambda_{m}\left(1+\lambda_{m}(1-\delta)\right)\left[\lambda_{m}^{2} \delta\left(3-\tau^{2} / h\right)+\lambda_{m}^{2} \delta+\left(1+\lambda_{m}\right)(1+\delta)\left(4-\tau^{2} / h\right)+\lambda_{m}\right](a-c)^{2}}{\left[\left(1+\lambda_{m}\right)(1+\delta)\left(4-\tau^{2} / h\right)+\lambda_{m}^{2} \delta\left(2-\tau^{2} / h\right)+2 \lambda_{m}\left(1+\lambda_{m}\right)\right]^{2}\left(4-\tau^{2} / h\right)^{2}} \\
& =-\frac{4 \lambda_{m}\left(1+\lambda_{m}(1-\delta)\right)\left[\lambda_{m}^{2} \delta\left(4-\tau^{2} / h\right)+\left(1+\lambda_{m}\right)(1+\delta)\left(4-\tau^{2} / h\right)+\lambda_{m}\right](a-c)^{2}}{\left[\left(1+\lambda_{m}\right)(1+\delta)\left(4-\tau^{2} / h\right)+\lambda_{m}^{2} \delta\left(2-\tau^{2} / h\right)+2 \lambda_{m}\left(1+\lambda_{m}\right)\right]^{2}\left(4-\tau^{2} / h\right)^{2}} .
\end{aligned}
$$

In Section 3.1.2, we have $0<\tau^{2} / h<4$. Thus, we have $\pi_{r, \lambda_{m}}^{D *}<\pi_{r}^{D}$.

For case (iii), it follows from (14) and (26) that:

$$
\begin{aligned}
\pi_{s c, \lambda_{m}}^{D *}-\pi_{s c}^{D} & =-\frac{2 h^{3}\left(1+\lambda_{m}(1-\delta)\right)\left[\left(2\left(\delta \lambda_{m}+\delta+1\right)+\lambda_{m}\left(3+\lambda_{m}\right)\right)\left(4 h-\tau^{2}\right)+\lambda_{m}^{2} \delta\left(2 h-\tau^{2}\right)+2 h \lambda_{m}\left(1+\lambda_{m}\right)\right](a-c)^{2}}{2\left[\left(1+\lambda_{m}\right)(1+\delta)\left(4 h-\tau^{2}\right)+\lambda_{m}^{2} \delta\left(2 h-\tau^{2}\right)+2 h \lambda_{m}\left(1+\lambda_{m}\right)\right]^{2} 2\left(4 h-\tau^{2}\right)^{2}} \\
& =-\frac{2\left(1+\lambda_{m}(1-\delta)\right)\left[\left(2\left(\delta \lambda_{m}+\delta+1\right)+\lambda_{m}\left(3+\lambda_{m}\right)\right)\left(4-\tau^{2} / h\right)+\lambda_{m}^{2} \delta\left(2-\tau^{2} / h\right)+2 \lambda_{m}\left(1+\lambda_{m}\right)\right](a-c)^{2}}{2\left(\left(1+\lambda_{m}\right)(1+\delta)\left(4-\tau^{2} / h\right)+\lambda_{m}^{2} \delta\left(2-\tau^{2} / h\right)+2 \lambda_{m}\left(1+\lambda_{m}\right)\right)^{2} 2\left(4-\tau^{2} / h\right)^{2}} \\
& =-\frac{2\left(1+\lambda_{m}(1-\delta)\right)\left[\left(2\left(\delta \lambda_{m}+\delta+1\right)+\lambda_{m}\left(3+\lambda_{m}\right)\right)\left(4-\tau^{2} / h\right)+\lambda_{m}^{2} \delta\left(2-\tau^{2} / h\right)+2 \lambda_{m}^{2}+2 \lambda_{m}\right](a-c)^{2}}{2\left(\left(1+\lambda_{m}\right)(1+\delta)\left(4-\tau^{2} / h\right)+\lambda_{m}^{2} \delta\left(2-\tau^{2} / h\right)+2 \lambda_{m}\left(1+\lambda_{m}\right)\right)^{2} 2\left(4-\tau^{2} / h\right)^{2}} \\
& <-\frac{2\left(1+\lambda_{m}(1-\delta)\right)\left[\left(2\left(\delta \lambda_{m}+\delta+1\right)+\lambda_{m}\left(3+\lambda_{m}\right)\right)\left(4-\tau^{2} / h\right)+\lambda_{m}^{2} \delta\left(2-\tau^{2} / h\right)+2 \lambda_{m}^{2} \delta+2 \lambda_{m}\right](a-c)^{2}}{2\left(\left(1+\lambda_{m}\right)(1+\delta)\left(4-\tau^{2} / h\right)+\lambda_{m}^{2} \delta\left(2-\tau^{2} / h\right)+2 \lambda_{m}\left(1+\lambda_{m}\right)\right)^{2} 2\left(4-\tau^{2} / h\right)^{2}} \\
& <-\frac{2\left(1+\lambda_{m}(1-\delta)\right)\left[\left(2\left(\delta \lambda_{m}+\delta+1\right)+\lambda_{m}\left(3+\lambda_{m}\right)\right)\left(4-\tau^{2} / h\right)+\lambda_{m}^{2} \delta\left(4-\tau^{2} / h\right)+2 \lambda_{m}\right](a-c)^{2}}{2\left(\left(1+\lambda_{m}\right)(1+\delta)\left(4-\tau^{2} / h\right)+\lambda_{m}^{2} \delta\left(2-\tau^{2} / h\right)+2 \lambda_{m}\left(1+\lambda_{m}\right)\right)^{2} 2\left(4-\tau^{2} / h\right)^{2}} .
\end{aligned}
$$

In Section 3.1.1, we have $0<\tau^{2} / h<2$. Then, we have $\pi_{s c, \lambda_{m}}^{D *}<\pi_{s c}^{D}$. 
It follows from (7) and (14) that:

$$
\pi_{s c}^{D}-\pi_{s c}\left(p^{*}, e^{*}\right)=-\frac{2 h^{3}(a-c)^{2}}{\left(4 h-\tau^{2}\right)^{2}\left(2 h-\tau^{2}\right)}=-\frac{2(a-c)^{2}}{\left(4-\tau^{2} / h\right)^{2}\left(2-\tau^{2} / h\right)} .
$$

In Section 3.1.1, we have $0<\tau^{2} / h<2$. Then, we have $\pi_{s c}^{D}<\pi_{s c}\left(p^{*}, e^{*}\right)$.

Thus, we have $\pi_{s c, \lambda_{m}}^{D *}<\pi_{s c}^{D}<\pi_{s c}\left(p^{*}, e^{*}\right)$.

\section{Appendix F. Proof of Proposition 5}

Taking the second derivative of (39) with respect to $\varphi$ yields:

$$
\begin{aligned}
\frac{\partial^{2}\left(\pi_{r, \lambda_{m}}^{\phi, D *}\right)}{\partial \phi^{2}}= & -\frac{1}{\left[2\left(\lambda_{m}^{2}+(2+\delta) \lambda_{m}+1+\delta-A\right) C h+A^{2} \tau^{2}\right]^{4}}\left\{2 h^{2} \tau^{2}\left(1+\lambda_{m}\right)\left(1+\lambda_{m}+\delta\right)\left(\delta \lambda_{m}^{2}+\delta \lambda_{m}+\lambda_{m}+\delta+1\right)^{4} \times\right. \\
& {\left[2 h\left(1+\lambda_{m}\right)\left(1+\lambda_{m}+\delta\right)\left(\delta \lambda_{m}^{2}+2 \delta \lambda_{m}+3 \lambda_{m}^{2}+3 \lambda_{m}+2 \delta+2\right)\left(\delta \lambda_{m}^{2}+4 \delta \lambda_{m}+3 \lambda_{m}^{2}+7 \lambda_{m}+4 \delta+4\right) \phi+\right.} \\
& \left(\delta \lambda_{m}^{2}+\delta \lambda_{m}+\lambda_{m}+\delta+1\right)^{2}\left(2 \delta \lambda_{m}^{2}+5 \delta \lambda_{m}+\lambda_{m}^{2}+8 \lambda_{m}+5 \delta+5\right)\left(2 h-\tau^{2}\right)- \\
& \left.\left.2 h\left(\delta \lambda_{m}^{2}+\delta \lambda_{m}+\lambda_{m}+\delta+1\right)^{2}\left(\delta \lambda_{m}^{2}+2 \delta \lambda_{m}+\lambda_{m}^{2}+3 \lambda_{m}+2 \delta+2\right)\right]\right\} .
\end{aligned}
$$

From (34), it follows that $\frac{\partial^{2}\left(\pi_{r, \lambda m}^{\phi, D *}\right)}{\partial \phi^{2}}<0$. Then, there exists the optimal proportion of greening cost that the retailer shares with the manufacturer. After taking the first derivative of (39) with respect to $\varphi$ and letting this derivative be equal to zero, the optimal proportion of greening cost that the retailer shares with the manufacturer is:

$$
\phi_{\lambda_{m}}^{*}=\frac{2 h\left(1+\lambda_{m}\right)\left(1+\lambda_{m}+\delta\right)\left(\delta \lambda_{m}^{2}+\delta \lambda_{m}+\lambda_{m}+\delta+1\right)-\left(\delta \lambda_{m}^{2}+\delta \lambda_{m}+\lambda_{m}+\delta+1\right)^{2}\left(2 h-\tau^{2}\right)}{2\left(1+\lambda_{m}\right)\left(1+\lambda_{m}+\delta\right)\left(\delta \lambda_{m}^{2}+4 \delta \lambda_{m}+3 \lambda_{m}^{2}+4 \delta+7 \lambda_{m}+4\right) h} .
$$

\section{Appendix G. Proof of Proposition 6}

Let $\lambda_{m}=0$ mean that the manufacturer is risk-neutral. Then, the optimal proportion of greening cost that the retailer shares with a risk-neutral manufacturer is $\phi^{*}=\tau^{2} /(8 h)$. On the other hand, if $\delta$ $\rightarrow 1$, then:

$$
\phi_{\lambda_{m}}^{*}-\phi^{*}=\frac{\lambda_{m}\left[\left(8-7 \tau^{2} / h\right) \lambda_{m}^{2}+\left(16-17 \tau^{2} / h\right) \lambda_{m}+2\left(8-7 \tau^{2} / h\right)\right]}{8\left(1+\lambda_{m}\right)\left(2+\lambda_{m}\right)\left(4 \lambda_{m}^{2}+11 \lambda_{m}+8\right)} .
$$

Since $\left(8-7 \tau^{2} / h\right) \lambda_{m}^{2}+\left(16-17 \tau^{2} / h\right) \lambda_{m}+2\left(8-7 \tau^{2} / h\right)=\left(8-7 \tau^{2} / h\right)\left(\lambda_{m}^{2}+2 \lambda_{m}+2\right)-3 \tau^{2} / h$, then we have the following two cases:

- $\tau^{2} / h \geq 8 / 7$. This implies $8-7 \tau^{2} / h \leq 0$. Thus, $\left(8-7 \tau^{2} / h\right) \lambda_{m}^{2}+\left(16-17 \tau^{2} / h\right) \lambda_{m}+2(8-$ $\left.7 \tau^{2} / h\right)<0$, which means that $\phi_{\lambda_{m}}^{*}<\phi^{*}$.

- $\tau^{2} / h<8 / 7$. There are the following three subcases:

Subcase $(i): \lambda_{m}^{2}+2 \lambda_{m}+2>\left(3 \tau^{2} / h\right) /\left(8-7 \tau^{2} / h\right)$. It means that $\phi_{\lambda_{m}^{*}}^{*}>\phi^{*}$.

Subcase (ii): $\lambda_{m}^{2}+2 \lambda_{m}+2<\left(3 \tau^{2} / h\right) /\left(8-7 \tau^{2} / h\right)$. It means that $\phi_{\lambda_{m}}^{*}<\phi^{*}$.

Subcase (iii): $\lambda_{m}^{2}+2 \lambda_{m}+2=\left(3 \tau^{2} / h\right) /\left(8-7 \tau^{2} / h\right)$. It means that $\phi_{\lambda_{m}}^{*}=\phi^{*}$.

\section{References}

1. Biswas, A.; Roy, M. Green products: An exploratory study on the consumer behaviour in emerging economies of the east. J. Clean. Prod. 2015, 87, 463-468. [CrossRef]

2. Zhu, Q.; Cote, R.P. Integrating green supply chain management into an embryonic eco-industrial development: A case study of the guitang group. J. Clean. Prod. 2004, 12, 1025-1035. [CrossRef]

3. El Saadany, A.M.; Jaber, M.Y. A production/remanufacturing inventory model with price and quality dependant return rate. Comput. Ind. Eng. 2010, 58, 352-362. [CrossRef] 
4. Hall, J.; Vredenburg, H. The challenges of innovating for sustainable development. Mit Sloan Manag. Rev. 2003, 45, 61-68.

5. Guide, V.D.; Wassenhove, L.N. Closed-loop supply chains: An introduction to the feature issue (part 1). Prod. Oper. Manag. 2006, 15, 345-350. [CrossRef]

6. Östlin, J.; Sundin, E.; Björkman, M. Importance of closed-loop supply chain relationships for product remanufacturing. Int. J. Prod. Econ. 2008, 115, 336-348. [CrossRef]

7. Li, B.; Zhu, M.; Jiang, Y.; Li, Z. Pricing policies of a competitive dual-channel green supply chain. J. Clean. Prod. 2016, 112, 2029-2042. [CrossRef]

8. Lin, P.C.; Huang, Y.H. The influence factors on choice behavior regarding green products based on the theory of consumption values. J. Clean. Prod. 2012, 22, 11-18. [CrossRef]

9. Zhang, L.; Wang, J.; You, J. Consumer environmental awareness and channel coordination with two substitutable products. Eur. J. Oper. Res. 2015, 241, 63-73. [CrossRef]

10. Yu, Y.; Han, X.; Hu, G. Optimal production for manufacturers considering consumer environmental awareness and green subsidies. Int. J. Prod. Econ. 2016, 182, 397-408. [CrossRef]

11. Pujari, D. Eco-innovation and new product development: Understanding the influences on market per-formance. Technovation 2006, 26, 76-85. [CrossRef]

12. Banker, R.D.; Khosla, I.; Sinha, K.K. Quality and competition. Manag. Sci. 1998, 44, 1179-1192. [CrossRef]

13. Ghosh, D.; Shah, J. A comparative analysis of greening policies across supply chain structures. Int. J. Prod. Econ. 2012, 135, 568-583. [CrossRef]

14. Wilkerson, T. Best Practices in Implementing Green Supply Chains. In North America Supply Chain World Conference and Exposition. 5 April 2005. Available online: http:/ / postconflict.unep.ch/humanitarianaction/ documents /02_08-04_05-25.pdf (accessed on 28 May 2011).

15. Tan, C.; Yi, W.; Chen, X. Bertrand game under a fuzzy environment. J. Intell. Fuzzy Syts. 2018, 34, $2611-2624$. [CrossRef]

16. Kahneman, D.; Tversky, A. Prospect Theory: An analysis of decision under risk. Econometrica 1979, 47, 263-291. [CrossRef]

17. Cui, C.; Zhongwei Feng, Z.; Tan, C.; Borkotokey, S. Loss Aversion Equilibrium of Bimatrix Games withSymmetric Triangular Fuzzy Payoffs. Int. J. Fuzzy Syst. 2019. [CrossRef]

18. Tan, C.; Liu, Z.; Wu, D.D.; Chen, X. Cournot game with incomplete information based on rank-dependent utility theory under a fuzzy environment. Int. J. Prod. Res. 2018, 56, 1789-1805. [CrossRef]

19. Tversky, A.; Kahneman, D. Advances in Prospect Theory: Cumulative representation of uncertainty. J. Risk Uncertain. 1992, 5, 297-323. [CrossRef]

20. Shalev, J. Loss aversion equilibrium. Int. J. Game Theory 2000, 29, 269-287. [CrossRef]

21. Peters, H. A preference foundation for constant loss aversion. J. Math. Econ. 2012, 48, 21-25. [CrossRef]

22. Tversky, A.; Kahneman, D. The framing of decisions and the psychology of choice. Science 1981, 211, $453-458$. [CrossRef] [PubMed]

23. Rubinstein, A. Perfect equilibrium in a bargaining model. Econ. J. Econ. Soc. 1982, 50, 97-109. [CrossRef]

24. Driesen, B.; Perea, A.; Peters, H. Alternating offers bargaining with loss aversion. Math. Soc. Sci. 2012, 64, 103-118. [CrossRef]

25. Huang, Z.; Li, S.X. Co-op advertising models in manufacturer-retailer supply chains: A game theory approach. Eur. J. Oper. Res. 2001, 135, 527-544. [CrossRef]

26. Du, S.; Nie, T.; Chu, C.; Yu, Y. Newsvendor model for a dyadic supply chain with Nash bargaining fairness concerns. Int. J. Prod. Res. 2014, 52, 5070-5085. [CrossRef]

27. Song, H.; Gao, X. Green supply chain game model and analysis under revenue-sharing contract. J. Clean. Prod. 2018, 170, 183-192. [CrossRef]

28. Liu, P.; Yi, S.P. Pricing policies of green supply chain considering targeted advertising and product green degree in the big data environment. J. Clean. Prod. 2017, 164, 1614-1622. [CrossRef]

29. Ghosh, D.; Shah, J. Supply chain analysis under green sensitive consumer demand and cost sharing contract. Int. J. Prod. Econ. 2015, 164, 319-329. [CrossRef]

30. Basiri, Z.; Heydari, J. A mathematical model for green supply chain coordination with substitutable products. J. Clean. Prod. 2017, 145, 232-249. [CrossRef]

31. Sheu, J.B.; Chen, Y.J. Impact of government financial intervention on competition among green supply chains. Int. J. Prod. Econ. 2012, 138, 201-213. [CrossRef] 
32. Yang, D.; Xiao, T. Pricing and green level decisions of a green supply chain with governmental interventions under fuzzy uncertainties. J. Clean. Prod. 2017, 149, 1174-1187. [CrossRef]

33. Jamali, M.B.; Rasti-Barzoki, M. A game theoretic approach for green and non-green product pricing in chain-to-chain competitive sustainable and regular dual-channel supply chains. J. Clean. Prod. 2018, 170, 1029-1043. [CrossRef]

34. Xing, W.; Zou, J.; Liu, T.L. Integrated or decentralized: An analysis of channel structure for green products. Comput. Ind. Eng. 2017, 112, 20-34. [CrossRef]

35. Dai, R.; Zhang, J.; Tang, W. Cartelization or cost-sharing? Comparison of cooperation modes in a green supply chain. J. Clean. Prod. 2017, 156, 159-173. [CrossRef]

36. Eeckhoudt, L.; Gollier, C.; Schlesinger, H. The risk-averse (and prudent) newsboy. Manag. Sci. 1995, 41, 786-794. [CrossRef]

37. Schweitzer, M.E.; Cachon, G.P. Decision bias in the newsvendor problem with a known demand distribution: Experimental evidence. Manag. Sci. 2000, 46, 404-420. [CrossRef]

38. Suo, H.; Wang, J.; Jin, Y. Coordinating a loss-averse newsvendor with vendor managed inventory. In Proceedings of the 2004 IEEE International Conference on Systems, Man and Cybernetics, The Hague, The Netherlands, 10-13 October 2004; Volume 7, pp. 6026-6030.

39. Wang, C.X.; Webster, S. Channel coordination for a supply chain with a risk-neutral manufacturer and a loss-averse retailer. Decis. Sci. 2007, 38, 361-389. [CrossRef]

40. Wang, C.X.; Webster, S. The loss-averse newsvendor problem. Omega 2009, 37, 93-105. [CrossRef]

41. Wu, J.; Wang, S.; Chao, X.; Ng, C.T.; Cheng TC, E. Impact of risk aversion on optimal decisions in supply contracts. Int. J. Prod. Econ. 2010, 128, 569-576. [CrossRef]

42. Du, S.; Zhu, Y.; Nie, T.; Yu, H. Loss-averse preferences in a two-echelon supply chain with yield risk and demand uncertainty. Oper. Res. 2018, 18, 361-388. [CrossRef]

43. Yang, L.; Wang, G.; Ke, C. Remanufacturing and promotion in dual-channel supply chains under cap-and-trade regulation. J. Clean. Prod. 2018, 204, 939-957. [CrossRef]

44. Liu, Z.L.; Anderson, T.D.; Cruz, J.M. Consumer environmental awareness and competition in two-stage supply chains. Eur. J. Oper. Res. 2012, 218, 602-613. [CrossRef]

45. Swami, S.; Shah, J. Channel coordination in green supply chain management. J. Oper. Res. Soc. 2013, 64, 336-351. [CrossRef]

46. Dey, K.; Saha, S. Influence of procurement decisions in two-period green supply chain. J. Clean. Prod. 2018, 190, 388-402. [CrossRef] 